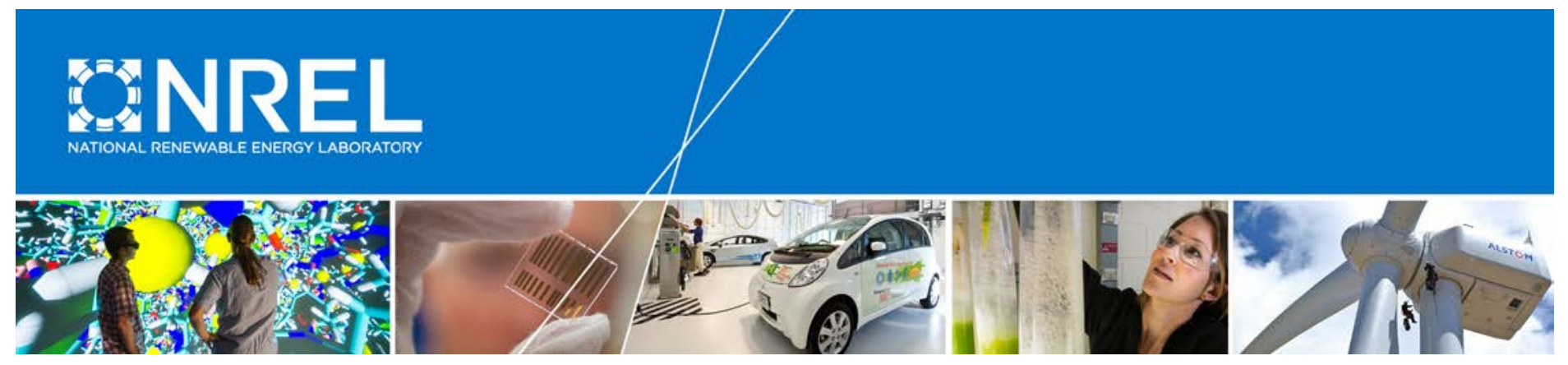

\title{
Overgeneration from Solar Energy in California: A Field Guide to the Duck Chart
}

Paul Denholm, Matthew O'Connell, Gregory Brinkman, and Jennie Jorgenson National Renewable Energy Laboratory

NREL is a national laboratory of the U.S. Department of Energy Office of Energy Efficiency \& Renewable Energy Operated by the Alliance for Sustainable Energy, LLC

This report is available at no cost from the National Renewable Energy Laboratory (NREL) at www.nrel.gov/publications.

Technical Report

NREL/TP-6A20-65023

November 2015 


\section{Overgeneration from Solar Energy in California: A Field Guide to the Duck Chart}

Paul Denholm, Matthew O'Connell, Gregory Brinkman, and Jennie Jorgenson National Renewable Energy Laboratory

Prepared under Task No. TM13.5020
NREL is a national laboratory of the U.S. Department of Energy Office of Energy Efficiency \& Renewable Energy Operated by the Alliance for Sustainable Energy, LLC

This report is available at no cost from the National Renewable Energy Laboratory (NREL) at www.nrel.gov/publications.

\section{Technical Report}

NREL/TP-6A20-65023

November 2015

Contract No. DE-AC36-08G028308
National Renewable Energy Laboratory 15013 Denver West Parkway

303-275-3000 • www.nrel.gov 


\title{
NOTICE
}

This report was prepared as an account of work sponsored by an agency of the United States government. Neither the United States government nor any agency thereof, nor any of their employees, makes any warranty, express or implied, or assumes any legal liability or responsibility for the accuracy, completeness, or usefulness of any information, apparatus, product, or process disclosed, or represents that its use would not infringe privately owned rights. Reference herein to any specific commercial product, process, or service by trade name, trademark, manufacturer, or otherwise does not necessarily constitute or imply its endorsement, recommendation, or favoring by the United States government or any agency thereof. The views and opinions of authors expressed herein do not necessarily state or reflect those of the United States government or any agency thereof.

This report is available at no cost from the National Renewable Energy Laboratory (NREL) at www.nrel.gov/publications.

Available electronically at SciTech Connect http:/www.osti.gov/scitech

Available for a processing fee to U.S. Department of Energy and its contractors, in paper, from:

\author{
U.S. Department of Energy \\ Office of Scientific and Technical Information \\ P.O. Box 62 \\ Oak Ridge, TN 37831-0062 \\ OSTI http://www.osti.gov \\ Phone: 865.576.8401 \\ Fax: 865.576.5728 \\ Email: reports@osti.gov
}

Available for sale to the public, in paper, from:

\author{
U.S. Department of Commerce \\ National Technical Information Service \\ 5301 Shawnee Road \\ Alexandria, VA 22312 \\ NTIS http://www.ntis.gov \\ Phone: 800.553 .6847 or 703.605 .6000 \\ Fax: 703.605.6900 \\ Email: orders@ntis.gov
}




\section{Acknowledgements}

This work was funded by the Solar Energy Technologies Office and the Office of Strategic Programs of the U.S. Department of Energy's (DOE) Office of Energy Efficiency and Renewable Energy (EERE) under contract number DE-AC36-08GO28308.

Thanks to Jimmy Nelson, UCS, Elaine Hart, E3, and Jim Lazar, RAPP for original figures. For their reviews and comments, the authors would like to thank Mark Ahlstrom, Aaron Bloom, Jaquelin Cochran, Udi Helman, Ookie Ma, Robert Margolis, Mike Meshek, Mackay Miller, Dave Mooney, Jimmy Nelson and Charlie Smith.

\section{Abstract}

In 2013, the California Independent System Operator published the "duck chart," which shows a significant drop in mid-day net load on a spring day as solar photovoltaics (PV) are added to the system. The chart raises concerns that the conventional power system will be unable to accommodate the ramp rate and range needed to fully utilize solar energy, particularly on days characterized by the duck shape. This could result in "overgeneration" and curtailed renewable energy, increasing its costs and reducing its environmental benefits. This paper explores the duck chart in detail, examining how much PV might need to be curtailed if additional grid flexibility measures are not taken, and how curtailment rates can be decreased by changing grid operational practices. It finds that under business-as-usual types of assumptions and corresponding levels of grid flexibility in California, solar penetrations as low as $20 \%$ of annual energy could lead to marginal curtailment rates that exceed 30\%. However, by allowing (or requiring) distributed PV and storage (including new installations that are part of the California storage mandate) to provide grid services, system flexibility could be greatly enhanced. Doing so could significantly reduce curtailment and allow much greater penetration of variable generation resources in achieving a 50\% renewable portfolio standard. Overall, the work described in this paper points to the need to fully integrate distributed resources into grid system planning and operations to allow maximum use of the solar resource. 


\section{Table of Contents}

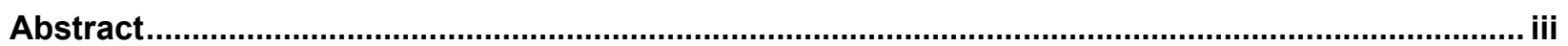

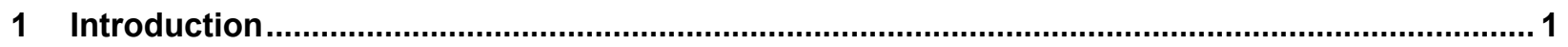

2 Background: Why Ducks Lead to Overgeneration .................................................................... 3

3 Previous Analysis of the California Duck and Estimates of Overgeneration ........................... 5

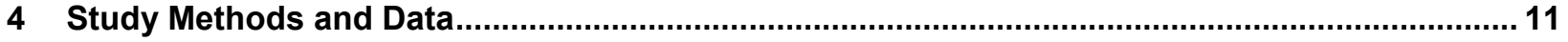

5 Results: Base “Most Conservative” Case ............................................................................. 13

6 Enabling Greater Solar Penetration: Flatten or Fatten the Duck?........................................... 24

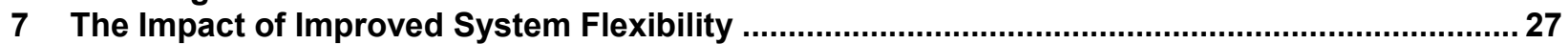

8 Additional Opportunities to Fatten and Flatten the Duck ...................................................... 35

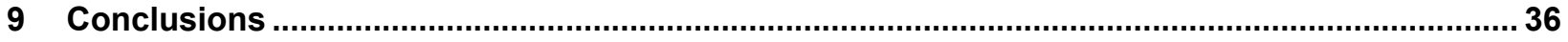

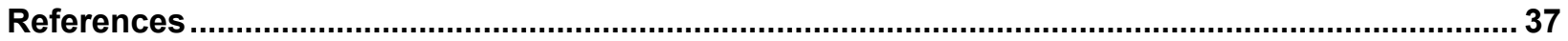




\section{List of Figures}

Figure 1. The CAISO duck chart

Figure 2. "Proto-duck" chart of California net load with increased penetration of PV ..................... 6

Figure 3. Example of an analysis of the impact of concentrating solar power (CSP) on the duck chart shape.

Figure 4. Example of the impact of changing system flexibility on demand shape and curtailment from an analysis by the Union of Concerned Scientists ............................................................... 8

Figure 5. Example of an analysis of the impact of high VG on net load shape and resulting overgeneration

igure 6. Example of an analysis of how the duck curve shape can be modified to minimize overgeneration

gure 7. Load, solar, and wind profiles for California on March 29 in a scenario with $11 \%$ annual

wind and $11 \%$ annual solar assuming no curtailment................................................................ 14

Figure 8. Modeled net load in California on March 29 in a scenario with $11 \%$ annual wind and $11 \%$ annual solar in a system with a $60 \%$ instantaneous penetration constraint ............................. 15

Figure 9. Used and curtailed VG in California on March 29 in a scenario with $11 \%$ annual wind and

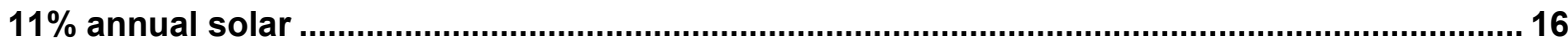

Figure 10. Instantaneous penetration of VG on March 29 with and without curtailment in a scenario with $11 \%$ annual wind and $11 \%$ annual solar ..................................................................... 17

Figure 11. Increase in VG use resulting from schedulable pumped storage in a scenario with $11 \%$

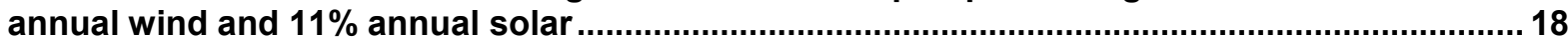

Figure 12. Load, solar, and wind profiles for California on July 27 in a scenario with $11 \%$ annual wind and $11 \%$ annual solar.

Figure 13. Instantaneous penetration of VG in California on July 27 in a scenario with $11 \%$ annual

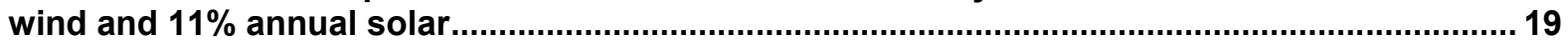

Figure 14. Load in California and VG Profiles on March 29 in a scenario with $11 \%$ and $15 \%$ annual

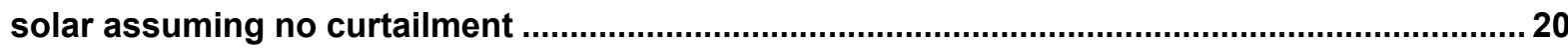

Figure 15. Net load on March 29 in a scenario with $11 \%$ and $15 \%$ annual solar considering operational constraints

Figure 16. Usable and curtailed VG on March 29 in a scenario with $11 \%$ and $15 \%$ potential annual solar.

igure 17. Marginal and average curtailment due to overgeneration under increasing penetration of PV in California with a $60 \%$ instantaneous penetration limit ............................................. 22

Figure 18. Marginal and average PV LCOE (based on SunShot goals) due to overgeneration under increasing penetration of PV in California with a $60 \%$ instantaneous penetration limit............. 23

Figure 19. Accommodation of increased penetration of PV by reducing system minimum

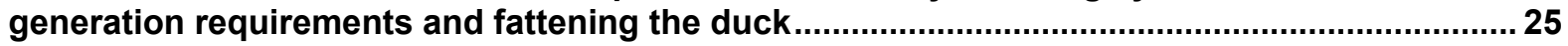

Figure 20. Accommodation of increased penetration of PV by flattening the duck (increasing mid-

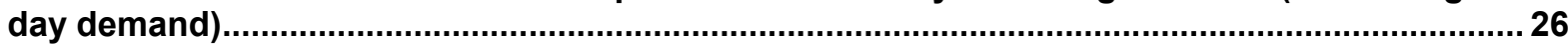

Figure 21. Impact of flattening the duck on March 29 with 1,285 MW of added storage in a scenario with $15 \%$ annual solar

Figure 22. Net load on March 29 in a scenario with $15 \%$ annual solar increasing the maximum

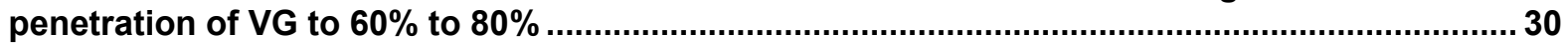

Figure 23. VG curtailment on March 29 in a scenario with $15 \%$ annual solar increasing the maximum penetration of VG to $60 \%$ to $80 \%$ and removing the local generation requirement .. 31

Figure 24. Marginal and average annual curtailment due to overgeneration under increasing penetration of $\mathrm{PV}$ in California after adding mandated storage, removing local generation constraint, and increasing maximum instantaneous VG penetration to $\mathbf{8 0} \%$... 22 


\section{Introduction}

In 2013, the California Independent System Operator (CAISO) published a chart showing the potential for "overgeneration" occurring at increased penetration of solar photovoltaics (PV). ${ }^{1}$ The "duck chart" shows the potential for PV to provide more energy than can be used by the system, especially considering the host of technical and institutional constraints on power system operation.

During overgeneration conditions, the supply of power could exceed demand, and without intervention, generators and certain motors connected to the grid would increase rotational speed, which can cause damage. To avoid this, system operators carefully balance supply with demand, increasing and reducing output from the conventional generation fleet. ${ }^{3}$ The overgeneration risk occurs when conventional dispatchable resources cannot be backed down further to accommodate the supply of variable generation (VG). Overgeneration has a relatively simple technical solution, often referred to as curtailment. Curtailment occurs when a system operator decreases the output from a wind or PV plant below what it would normally produce. For wind, this is performed by changing the energy captured from the wind (by changing the blade pitch angle) (Aho et al. 2012). For solar, generation is curtailed by either reducing output from the inverter or disconnecting the plant altogether. This of course requires a plant or system operator to have physical control of the generation resource, which is typically available for large renewable power plants but uncommon for smaller systems, particularly distributed or rooftop systems. While curtailment is technically easy, it has the obvious undesirable trait of reducing the economic and environmental benefits of VG. Each unit of VG curtailed represents a unit of energy not sold on to the grid and a unit of fossil fuel not avoided. As the amount of curtailment increases, the overall benefits of additional solar may drop to the point where additional installations are not worth the cost (Cochran et al. 2015).

Neither the potential for overgeneration, nor the resulting curtailment of variable generation resources is a new concern (Bird et al. 2014). However, the significant attention paid to the duck chart signals an important change in attitude toward integration of variable generation (VG). The duck chart represents perhaps the first major acknowledgement by a system operator that solar energy is no longer a niche technology (at least in California) and that curtailment will be a significant issue in the not-too-distant future. The chart has also raised general awareness of the issues associated with renewable curtailment and system flexibility.

The duck chart is largely illustrative in nature, representing only one day of the year, and it does not quantify the actual curtailment that may occur at increased penetration of solar energy. Nor does the chart reflect the impact of mitigation options.

In this work, we examine how the duck chart shape illustrates potential overgeneration risks in California at increased penetration of PV. We first review previous analyses of the impact of PV

\footnotetext{
${ }^{1}$ https://www.caiso.com/Documents/FlexibleResourcesHelpRenewables_FastFacts.pdf

2 The name is derived from its resemblance to the profile of a duck.

${ }^{3}$ Throughout this document, we use the term system operator to refer to the balancing area authorities responsible for balancing supply and demand through generator scheduling and dispatch. In California, the largest of these is the CAISO, but there are several other system operators, including Los Angeles Department of Water and Power, Imperial Irrigation District, Balancing Authority of Northern California, and Turlock Irrigation District.
} 
on load in California and potential PV curtailment at increased penetration. We then use a production cost model to quantify the amount of overgeneration that can result from the increased PV without measures to increase system flexibility. Finally, we show how the duck shape can be accommodated with different measures to increase flexibility-including flexibility that is provided by the PV itself under appropriate market rules - and how overgeneration risks can be dramatically reduced by introducing multiple flexibility measures. 


\section{Background: Why Ducks Lead to Overgeneration}

The CAISO duck chart itself illustrates the general challenge of accommodating solar energy and the potential for overgeneration and solar curtailment. In the chart, each line represents the net load, equal to the normal load minus wind and PV generation. The "belly" of the duck represents the period of lowest net load, where PV generation is at a maximum. The belly grows as PV installations increase between 2012 and 2020. While the amount of PV in 2020 is not shown directly, it can be estimated by comparing the 2012 curve to the 2020 curve. In this case, the normal load (i.e., no PV and adjustments for load growth) at about 1-2 p.m. on March 31, 2020 appears to be about 22,000 megawatts (MW), while PV is generating about 10,000 MW, leaving about $12,000 \mathrm{MW}$ to be met with other resources. In this case, PV provides perhaps $45 \%$ of the total demand in this one hour. The duck chart also points to the period of overgeneration risk, which could result in curtailed energy.

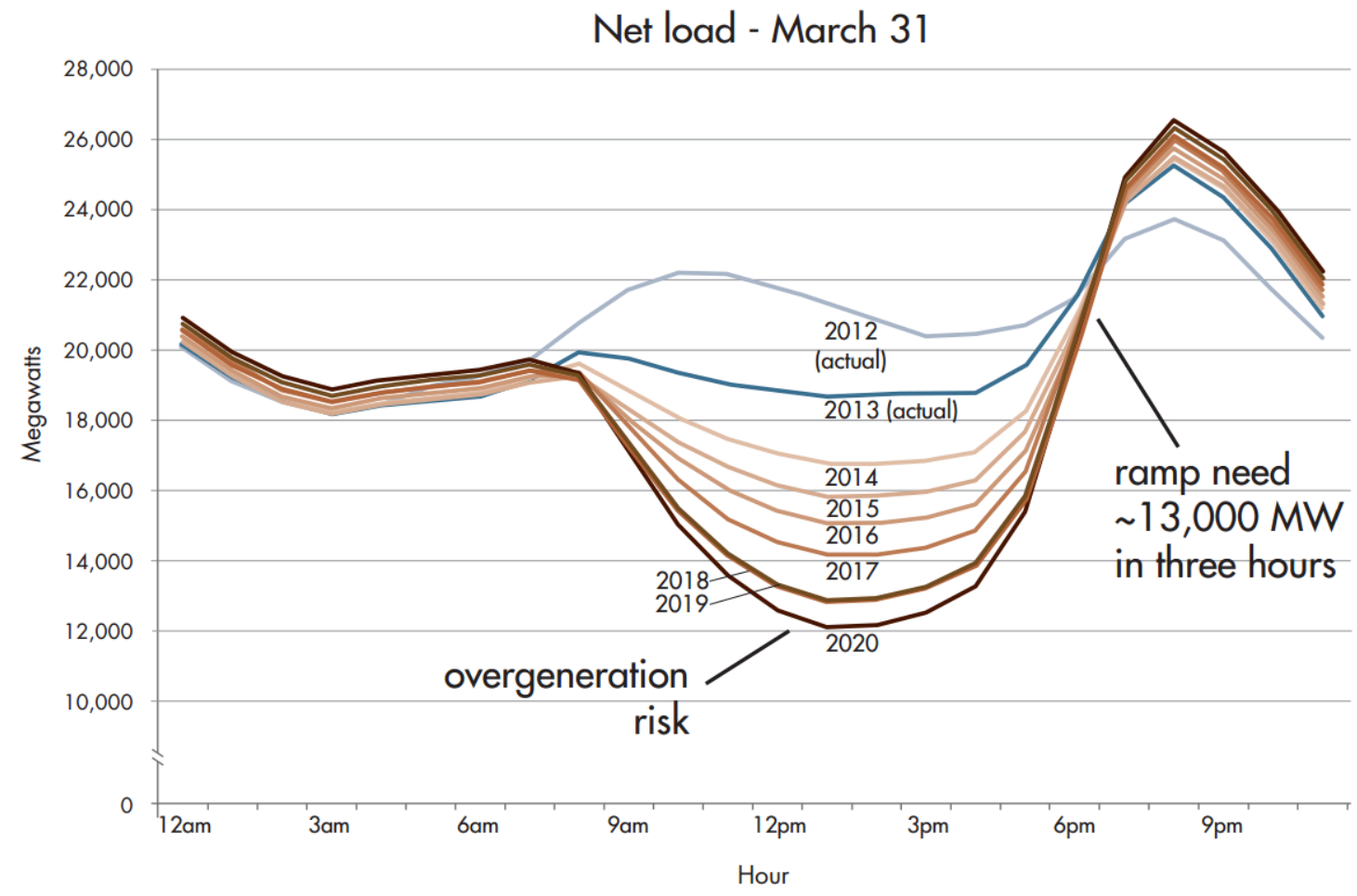

Figure 1. The CAISO duck chart

Source: CAISO 2013

The CAISO duck chart document does not explicitly quantify the amount of expected curtailment during this period, but it describes two main causes:

The first occurs as the ISO [independent system operator] prepares to meet the upcoming upward ramps [using conventional generation] that occur in the morning and in the late afternoon. The existing fleet includes many long-start resources that need time to come on line before they can support upcoming ramps. 
Therefore, they must produce at some minimum power output levels in times when this electricity is not needed. ${ }^{4}$

The second source of overgeneration and curtailment "occurs when output from any nondispatchable/must-take resource further increases supply in times of low electricity need, typically in the nighttime hours. Historically, this condition was most likely to occur in the early morning hours when low demand combines with electricity and generation brought on line to prepare for the morning ramp." This second challenge includes the need to accommodate output of all generation resources such as wind and hydro, and plants that produce heat and electricity. Overgeneration can also result from "must-run" plants that are needed for local voltage support and reliability issues, and also from a number of institutional constraints, such as long-term contracts and self-scheduling from certain power plants (GE Energy 2015; Bouillon 2014).

Combined, these issues create an operational challenge which can be described as the "minimum generation" problem which represents the technical and economic limits of thermal and hydro power plants to reduce output or turn off, especially during relatively short periods, such as the few hours of peak solar output. Other factors can produce curtailed VG, including transmission constraints, and at increased penetration of VG, conventional generators that must be online to maintain system stability. (This latter issue is discussed in Section 6).

Because of the economic challenges posed by curtailment, it becomes important to examine how much curtailment may occur, as well as methods to reduce curtailment. The ability to accommodate VG is largely determined by the flexibility of the power grid, and flexibility can be changed over time. Examining the relationship between system flexibility and curtailment can help determine the potential contribution of solar to meeting the energy requirements of a region such as California.

\footnotetext{
${ }^{4}$ https://www.caiso.com/Documents/FlexibleResourcesHelpRenewables_FastFacts.pdf
} 


\section{Previous Analysis of the California Duck and Estimates of Overgeneration}

There are a number of discussions of the California duck chart, and several estimates of curtailment that may result in California from increased penetration of PV. Several of these discussions are part of larger planning and integration studies that consider broader impacts of VG on the system (e.g., system economic and environmental benefits), areas of operational challenges (e.g., additional reserve requirements), and integration costs. Integration studies, along with general grid planning studies use grid-simulation tools that model the operation of the entire generation fleet (Sterling et al. 2013). These have a number of names, including "production cost" and "security-constrained unit commitment and economic dispatch" models (Denholm et al. 2014). ${ }^{5}$

We use the term production cost model (PCM) to represent the class of models that simulate the chronological operation of the power grid, determining which power plants to commit and dispatch during each time interval on the basis of forecasted fuel costs, heat rates and other operational characteristics. In each time interval, the model selects the least-cost mix of generators needed to meet load while maintaining adequate reserves to meet contingency events and other reserve requirements. Such models typically simulate the grid for one year of operation in 8,760 one-hour time steps. PCMs calculate the total cost of system operation, including cost of fuel and cost of operation and maintenance. ${ }^{6}$ To model the grid realistically, these tools require extensive databases of generator properties, transmission capacity, and system operational requirements, such as reserve requirements. In theory, a properly designed and implemented PCM simulation should produce results (such as generator dispatch, emissions, and total production costs) close to the dispatch resulting from the market operations or dispatch software used by independent system operators or balancing areas to actually control the grid. However, PCMs cannot completely simulate market environments because they typically do not capture self-scheduling, bilateral contracts, scarcity pricing, bidding strategies, and other factors that can alter system dispatch from the "least-cost" dispatch produced by a model.

An early attempt to model the increased penetration of PV in California using a production cost model is Denholm et al. (2008). This work uses the PROSYM PCM and demonstrates a "protoduck" chart showing a deep drop in mid-day net demand (Figure 2) that is similar to that in the CAISO duck chart. The net load during this two-day period is from slightly later in the spring (May 6-7), and with the higher solar output, represents the lowest net load of any point during the year. Despite the lower net load and higher ramp range compared to the CAISO duck chart, this analysis did not demonstrate any significant overgeneration or PV curtailment. This is due to a variety of favorable assumptions, including "frictionless" exchange of energy with the surrounding regions without restrictions other than the thermal limits of the transmission network. At the highest level of penetration, nearly half of the incremental PV generation in

\footnotetext{
${ }^{5}$ Various entities, including independent system operators use these models to simulate system operations for planning purposes. However these are a number of differences between how these models work and the market management software used for actual unit commitment and dispatch. An example is the generation of the commitment and dispatch "stack" (or merit order). Production cost models use plant-level estimates of variable costs while ISO operations use market bids from individual generators

${ }^{6}$ Production cost models only consider the variable costs of operating the system. Fixed costs (capital costs, fixed O\&M) are not considered.
} 
California is displacing out-of-state generation. In addition, while the model did include standard generator parameters (e.g., minimum generation and start-time constraints), it did not consider any institutional, contractual, or local reliability constraints that may exist within California.

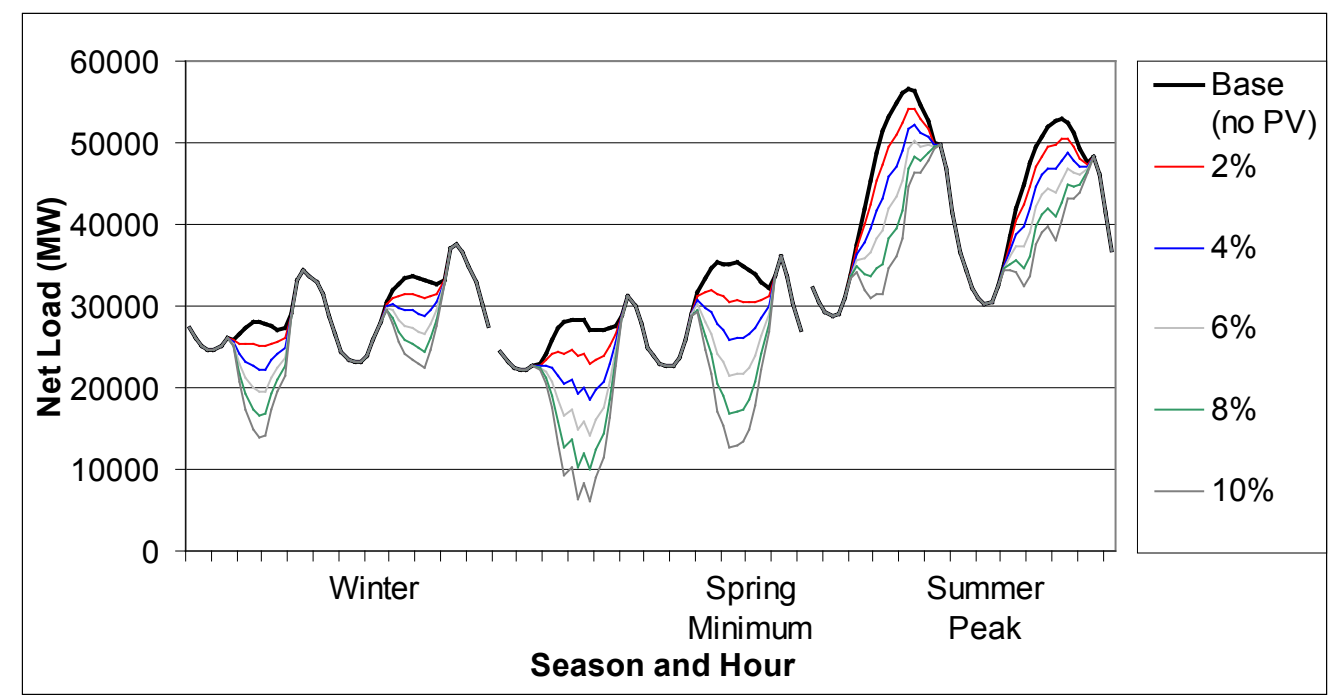

Figure 2. "Proto-duck" chart of California net load with increased penetration of PV

Source: Denholm et al. 2008

The 2013 duck chart and much of the concern regarding overgeneration originates with a series of studies published by the CAISO (CAISO 2010, 2011a, and 2011b, Liu 2014a, 2014b and 2014 c) and by emergence of negative prices in the CAISO market driven in part by growth in wind generation (CAISO 2012). The CAISO studies have examined the impacts of an increasing renewable portfolio standard (RPS) starting with $20 \%$, increasing to $33 \%$, and then $40 \%$, and they have demonstrated increasing levels of overgeneration risk. These studies use the PLEXOS production cost model, which is one of several commercially available grid simulation tools. CAISO produces and maintains a database for this model as part of the Long-Term Procurement Plan (LTPP). ${ }^{7}$ This database includes generator-level details of California's electricity sector as well the rest of the Western Interconnection. The CAISO has made its PLEXOS databases publicly available, and in addition to California utility studies (Mao and Galjanic 2014), several non-utility research groups have used them directly or in modified forms to analyze sensitivities to various assumptions. Table 1 summarizes several of the previous analyses using some form of the LTPP model.

\footnotetext{
${ }^{7}$ http://www.cpuc.ca.gov/PUC/energy/procurement/LTPP/ltpp_history.htm
} 
Table 1. Previous Studies Using the Long-Term Procurement Plan Database

\begin{tabular}{|l|l|l|}
\hline Study Lead Organization & Cite & Study Focus \\
\hline CAISO & $\begin{array}{l}\text { CAISO 2011a, CAISO } \\
\text { 2011b Liu 2014a, } \\
2014 \mathrm{a}\end{array}$ & $\begin{array}{l}\text { Multiple studies of a variety of renewable } \\
\text { portfolio standards considering production cost, } \\
\text { fuel use, emissions, system flexibility } \\
\text { requirements and other factors }\end{array}$ \\
\hline Argonne National Laboratory & Koritarov et al. 2013 & Value of advanced pumped hydro storage \\
\hline NREL & Denholm et al. 2013 & Value of concentrating solar power \\
\hline $\begin{array}{l}\text { Lawrence Livermore National } \\
\text { Laboratory }\end{array}$ & Edmunds et al. 2014 & $\begin{array}{l}\text { Value of multiple storage options and demand } \\
\text { response }\end{array}$ \\
\hline DNV KEMA (now DNV-GL) & Abrams et al. 2014 & Value of multiple storage technologies \\
\hline NREL & Jorgenson et al. 2014 & Impact and value of multiple solar technologies \\
\hline Southern California Edison & Mao and Galjanic 2014 & $\begin{array}{l}\text { Operational flexibility and flexible capacity } \\
\text { requirements }\end{array}$ \\
\hline Union of Concerned Scientists & $\begin{array}{l}\text { Nelson 2014, Nelson } \\
\text { and Wisland 2015 }\end{array}$ & $\begin{array}{l}\text { Multiple aspects of VG integration including } \\
\text { options to minimize overgeneration }\end{array}$ \\
\hline
\end{tabular}

Several of the studies listed in Table 1 have identified the impact of various individual technologies on the duck chart shape of net load. For example, Jorgenson et al. (2014) examined the impact of two different solar technologies on imports into CAISO under increased VG penetration, as illustrated in Figure 3.

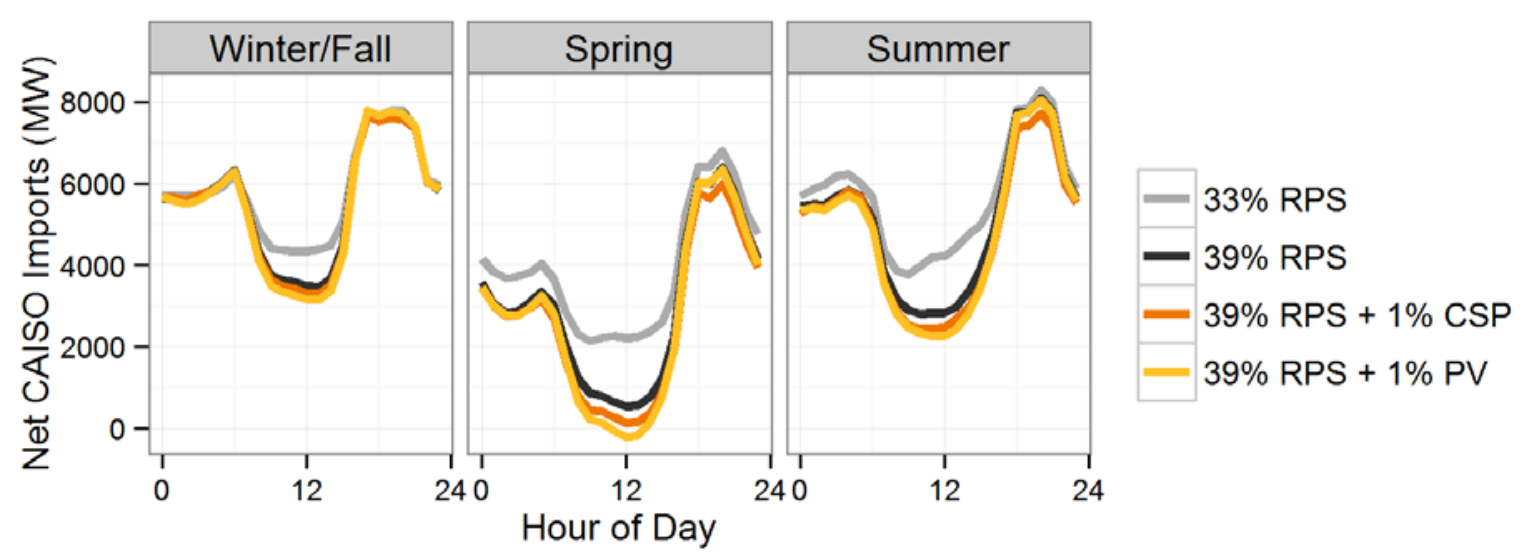

Figure 3. Example of an analysis of the impact of concentrating solar power (CSP) on the duck chart shape

Source: Jorgenson et al. 2014

Other groups have used the versions of the LTPP database to examine how increased grid flexibility could be used to minimize curtailment and enable higher levels of renewable penetration. For example, the Union of Concerned Scientists modified the LTPP database to simulate how increased flexibility could substantially reduce overgeneration risk in $40 \%$ and 50\% RPS scenarios (Nelson 2014; Nelson and Wisland 2015). 
Figure 4 illustrates an example from a 50\% RPS scenario, where increasing the amount of "nonfossil" sources of flexibility-including demand response, storage, provision of reserves from renewables $^{8}$, and exports - reduced curtailments by more than $75 \%$ compared to a base "inflexible" scenario and by $63 \%$ compared to a flexible gas scenario (Nelson and Wisland 2015). This figure shows an example day where adding flexibility options, including providing reserves with non-conventional resources, can reduce the minimum generation needed from hydro and gas generation, thereby reducing renewable curtailments.
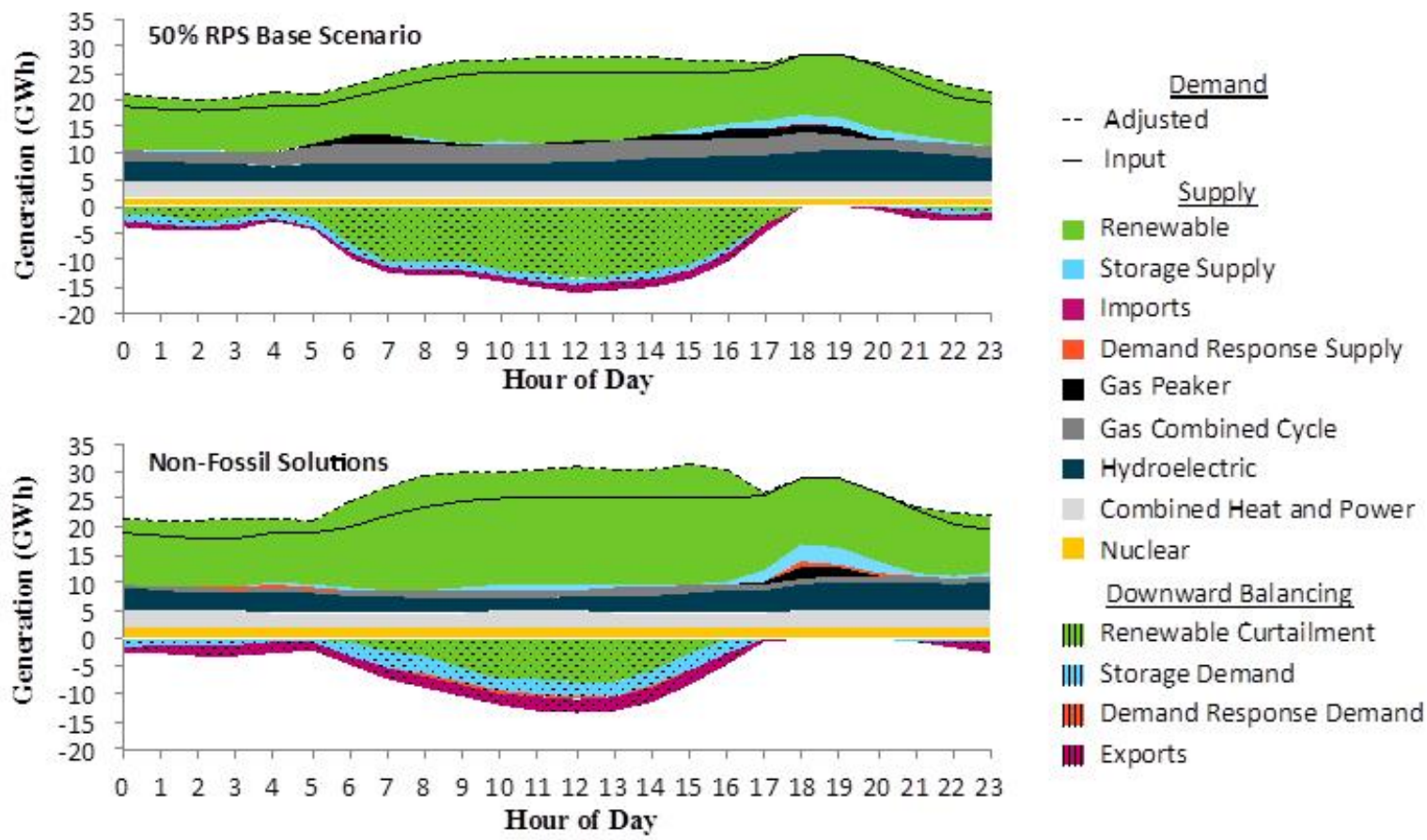

Figure 4. Example of the impact of changing system flexibility on demand shape and curtailment from an analysis by the Union of Concerned Scientists

(modified from Nelson and Wisland 2015)

Similarly, NREL has also examined higher renewable penetration scenarios in California using PLEXOS with a Western Interconnection database derived from the Western Electricity Coordinating Council (WECC) Transmission Expansion Policy Planning Committee (TEPPC), with additional modification based on the LTPP database (Brinkman et al. 2015). The NREL study examined cases where California achieves greater than $50 \%$ reduction in electric sector carbon dioxide emissions by 2030 with a variety of renewable energy technologies and flexibility assumptions, such as increased export limits and reduced minimum local generation requirements. Total annual curtailment estimates range from $0.2 \%$ (with a balanced portfolio in a more flexible grid) to almost 10\% (with a high-solar portfolio in a less flexible grid).

Other modeling tools have been applied to examine the impact of PV on overgeneration in California. A study by Energy \& Environmental Economics (E3 2014) using the ProMaxLT production cost model examined RPS levels higher than the previous CAISO studies. It

\footnotetext{
${ }^{8}$ Reserves from renewables, as discussed in later sections, involves using curtailed VG energy to provide upward reserve capacity, which is traditionally provided by partially loaded conventional generation.
} 
identified a significant increase in solar curtailment, particularly when mitigation options are not deployed. In one 50\% RPS scenario evaluated (with PV penetration equal to about $26 \%$ ), about $8.9 \%$ of available RPS energy is curtailed. The E3 study also observed that at the point that PV achieves this high level of penetration, the marginal curtailment (reflecting the curtailment rate of the last unit of PV added to the system) is as high as $65 \%$. Figure 5 provides an example from the E3 study showing a duck-shaped chart with a significant hump representing overgeneration.

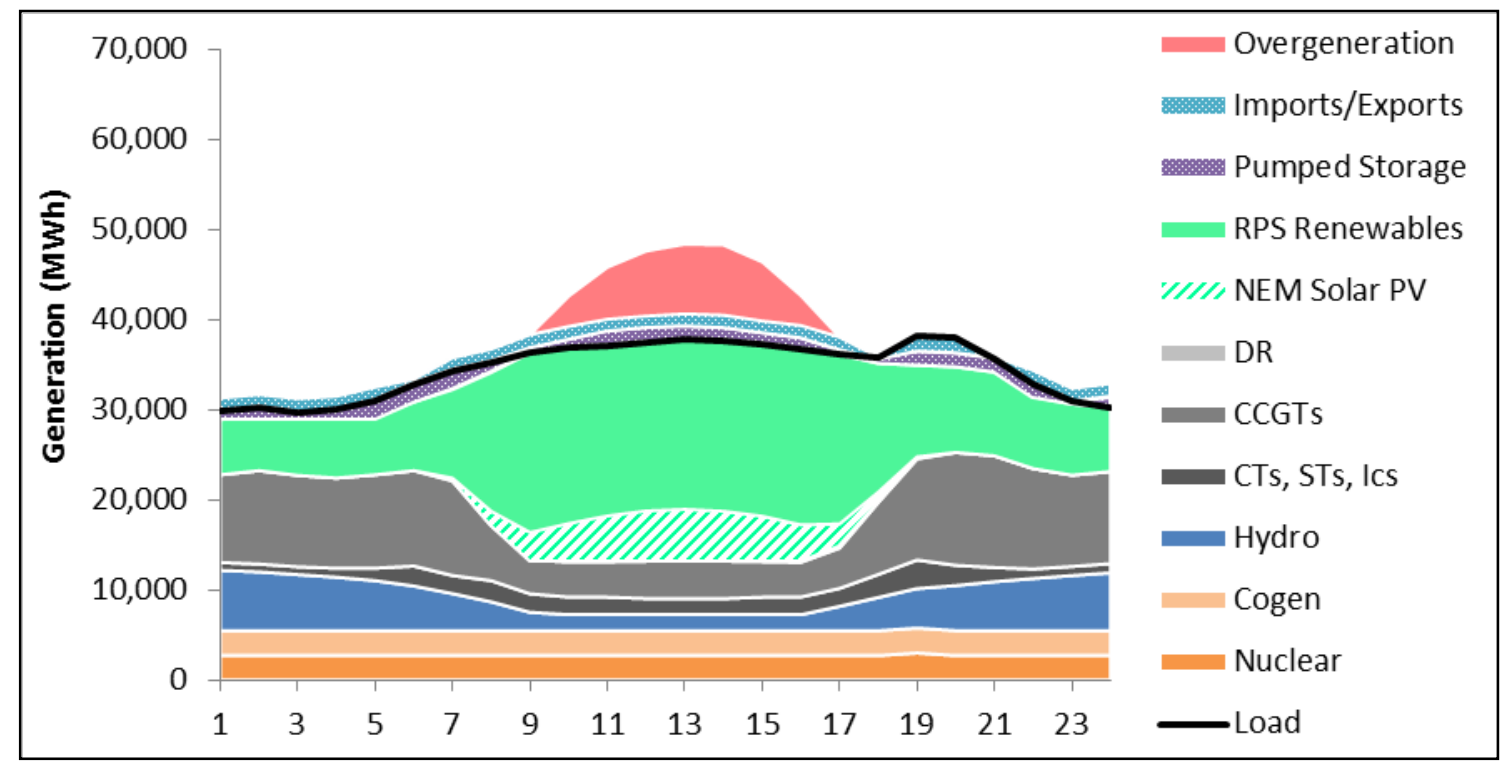

Figure 5. Example of an analysis of the impact of high VG on net load shape and resulting overgeneration

Source: E3 2014

This list includes only studies that have used commercial production cost models; however several other studies demonstrate the challenges associated with PV overgeneration in California. These include a study by Mills and Wiser (2012) that examines the overall decrease in value of $\mathrm{PV}$ as a function of penetration including the impacts of overgeneration, and a follow-on analysis that examines the impact of mitigation strategies including energy storage and demand response that effectively change the net load shape (Mills and Wiser 2014).

Finally, an extensive discussion of the duck chart shape and mitigation approaches is provided by Lazar (2014). While the analysis does not perform detailed operational simulations or estimate curtailment, it does provide a conceptual framework for changing the duck chart shape and flattening the net load through a total of 10 strategies including multiple types of energy storage and load shifting/demand response. An example of the analysis is provided in Figure 6, where the original duck shape is "streamlined" with the likely result of decreasing overgeneration and increasing the ability to integrate greater amounts of PV. Other discussions of mitigation options include Lew et al. (2015). 


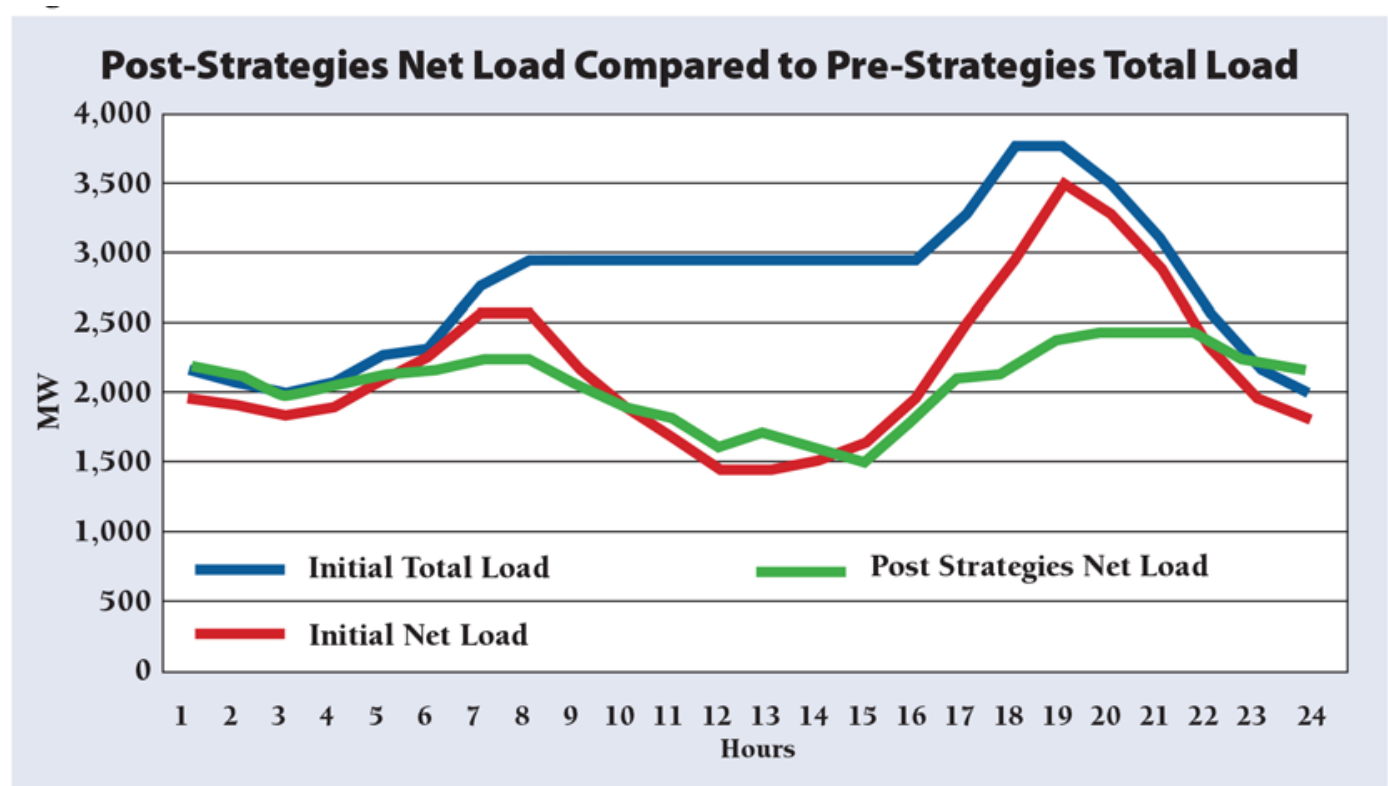

Figure 6. Example of an analysis of how the duck curve shape can be modified to minimize overgeneration

Source: Lazar 2014

It should also be noted that the impact of PV on net load and corresponding overgeneration risk have been studied in other parts of the United States, including Texas (Denholm and Margolis 2007), the entire Western Interconnection (GE 2010; Lew et al. 2013), and the Eastern United States (Bloom et al. 2015). 


\section{Study Methods and Data}

The goal of this study is to explore the duck curve in detail and identify the overgeneration and curtailment challenges associated specifically with increased deployment of solar energy in the California system. The study uses the PLEXOS production cost model ${ }^{9}$ to simulate grid operation with as more PV is added. It examines curtailment and considers how curtailment may change with alternative operational practices and technology deployment scenarios. The modeling framework and methods in this study are derived from the California 2030 Low Carbon Grid Study (Brinkman et al. 2015). The dataset for the analysis is based on a combination of the WECC TEPPC 2024 Common Case and the CAISO 2014 LTPP PLEXOS dataset. This dataset represents the power system in the entire Western Interconnection, while representing the California power system (transmission and generation) in more detail. Hurdle rates are included in the model based on the WECC 2024 Common Case to represent friction between balancing authorities. The analysis and results in this document represent all of California, including CAISO and the municipal utilities in California that are not part of CAISO.

The renewable generation is based on profiles developed for the Western Wind and Solar Integration Study and refined for Phase 2 of that study (Lew et al. 2012). The analysis performed hourly unit commitment and dispatch for 1 full year of simulation; however, sub-hourly renewable profiles were used to generate the day-ahead reserve requirements for up regulation and upward flexibility reserves. ${ }^{10}$

We begin by considering a scenario where wind provides about $11 \%$ of California's electricity. This represents a modest growth; in 2013, California generated 12.7 terawatt-hours (TWh) from wind in-state and imported another 12.7 TWh of wind for a total of $25.4 \mathrm{TWh}$, which provides about $8.6 \%$ of the total demand $(296.6 \mathrm{TWh}) .{ }^{11} \mathrm{We}$ also assume a total of about $1,900 \mathrm{MW}$ of concentrating solar power (CSP), which provides about $1.5 \%$ of total demand. Most of this CSP capacity does not have thermal storage, so it is considered a variable generation resource for this analysis. Other qualifying renewables (geothermal, biomass, and small hydro) provide about $13.6 \%$ of total demand. As a result, our initial (base) scenario represents a renewable potential of about $36 \%$, not including large hydro. To this base system, we incrementally add PV to analyze the progression of the duck chart shape and the resulting overgeneration, considering various changes to grid operation and conditions that can effect the net load shape. Table 2 summarizes the scenarios analyzed including renewable potential (before curtailment), and reserve requirements.

\footnotetext{
${ }^{9}$ Plexos V6.4 R01 x64 using the Xpress-MP 26.01.04 solver with a MIP relative gap of 0.5\%

${ }^{10}$ Following Brinkman et al. (2015), we do not enforce a downward reserve constraint, under the assumption that downward reserves can easily be provided by curtailing renewable energy generation during times when downward reserves are called. This assumption needs further analysis considering the actual curtailment that would result when using renewables for down reserves.

${ }^{11} \mathrm{http}$ ://energyalmanac.ca.gov/electricity/total_system power.html and http://energyalmanac.ca.gov/electricity/electricity_generation.html
} 
Table 2. Summary of PV Penetration Scenarios Evaluated

\begin{tabular}{|c|c|c|c|c|}
\hline $\begin{array}{l}\text { Solar Pre- } \\
\text { Curtailment } \\
\begin{array}{l}\text { Potential } \\
\text { Scenario (\%) }\end{array}\end{array}$ & $\begin{array}{l}\text { Total Solar (PV + } \\
\text { CSP) Potential } \\
\text { (GWh) }\end{array}$ & $\begin{array}{l}\text { Total Pre- } \\
\text { Curtailment RPS } \\
\text { Potential (\%) }\end{array}$ & $\begin{array}{l}\text { Annual } \\
\text { Regulation Up } \\
\text { Requirement } \\
\text { (GW-hr) }\end{array}$ & $\begin{array}{l}\text { Annual Flexiblity } \\
\text { Up Requirement } \\
\text { (GW-hr) }\end{array}$ \\
\hline $11 \%$ & 35,331 & $36.0 \%$ & 3,499 & 10,590 \\
\hline $15 \%$ & 46,473 & $39.6 \%$ & 3,671 & 11,089 \\
\hline $18 \%$ & 56,438 & $42.7 \%$ & 3,947 & 11,651 \\
\hline $21 \%$ & 66,155 & $45.8 \%$ & 4,282 & 12,240 \\
\hline $24 \%$ & 77,329 & $49.4 \%$ & 4,718 & 12,947 \\
\hline $31 \%$ & 98,964 & $56.3 \%$ & 5,652 & 14,361 \\
\hline $37 \%$ & 119,682 & $62.9 \%$ & 6,607 & 15,746 \\
\hline
\end{tabular}




\section{Results: Base "Most Conservative" Case}

We begin with an exploration of PV curtailment in a case with a set of conservative assumptions about power system operation based on a "2015 grid" without enhanced grid flexibility. These assumptions include:

- Wind and solar cannot provide upward reserves.

- No net exports of electricity from California are allowed and at least 70\% of California owned or contracted generation (including Hoover, Palo Verde and certain renewable generation) from outside of the state must be imported. ${ }^{12}$

- Up to about $1.3 \%$ of peak demand (as much as about $900 \mathrm{MW}$ during periods of peak demand) can be shifted via economic demand response programs. ${ }^{13}$

- No new storage is installed beyond what is in service in 2015 . $^{14}$

- Twenty-five percent of all generation within certain zones must be met with local thermal or hydro generation. ${ }^{15}$

- Diablo Canyon remains online as a baseload (non-dispatchable) generator. The plant does not contribute to the $25 \%$ local generation requirement. ${ }^{16}$

- Instantaneous penetration of VG (including PV, wind, and CSP without thermal energy storage) is limited to $60 \%$ of the normal load.

It should be noted that the CAISO does not include the $60 \%$ penetration limit in their formulation of the LTPP model; this limit is based on concerns stated in the CAISO duck chart fact sheet, indicating that at $60 \%$ penetration:

the grid may not be able to prevent frequency decline following the loss of a large conventional generator or transmission asset. This situation arises because renewable generators are not currently required to include automated frequency response capability and are operated at full output (they can not increase power). Without this automated capability, the system becomes increasingly exposed to blackouts when generation or transmission outages occur. ${ }^{17}$

\footnotetext{
${ }^{12}$ Following Brinkman et al. (2015) we allow non-imported VG to meet the California renewable requirement through the purchases of unbundled renewable energy credits (RECs). In the very high penetration cases described in the results, up to about $2 \%$ of renewable energy is not directly imported and acquired through RECs.

${ }^{13}$ This value is about equal to the existing "price response" demand response available from the three investorowned utilities in CAISO, as reported in the "Demand Response Monthly Reports" at (www.cpuc.ca.gov/PUC/energy/Demand+Response/Monthly+Reports/2015 DR.htm).

${ }^{14}$ The impact of storage mandated by California State Assembly Bill 2514 is discussed in the Section 6.

${ }^{15}$ In the database from which this study is derived (the Low Carbon Grid Study from Brinkman et al. 2015), the zones that require the 25\% local generation limit are SDGE, SCE, PG\&E (Valley Zone), and LADWP, which account for $77 \%$ of all California load. For additional analysis of the impact of the local generation requirement, see Nelson (2014) and Brinkman et al. (2015).

${ }^{16}$ This is a conservative assumption based on the fact that nuclear power plants typically do not vary load to provide operating reserves.

${ }^{17}$ https://www.caiso.com/Documents/FlexibleResourcesHelpRenewables_FastFacts.pdf
} 
We added this limit to our base case explicitly to examine its impact and the importance of changing grid operations to allow greater penetration of $\mathrm{VG}$ at any moment in time.

The combination of constraints on system operations can result in significant overgeneration, particularly in the spring. Figures 7-11 demonstrate the drivers behind overgeneration and PV curtailment in greater detail. Figure 7 shows the normal load, wind, and solar (combined PV and CSP) profiles in a scenario with the potential to meet $11 \%$ of annual demand from wind and $11 \%$ of the annual demand from solar (9.5\% from PV and 1.5\% from CSP). This figure is for March 29 , which is two days before the CAISO duck chart but actually the "worst" day in terms of PVdriven overgeneration for the load and PV demand patterns for this particularly meteorological year across all of California. (Because of the relatively low load, the potential generation from VG on this day is about $18 \%$ from solar and $16 \%$ from wind.) The figure also shows the resulting net load that would need to be met by the remaining generation fleet, assuming all solar and wind generation could be used. In this example, the new minimum load point (of about 7,700 MW) is shifted from 4 a.m. to noon.

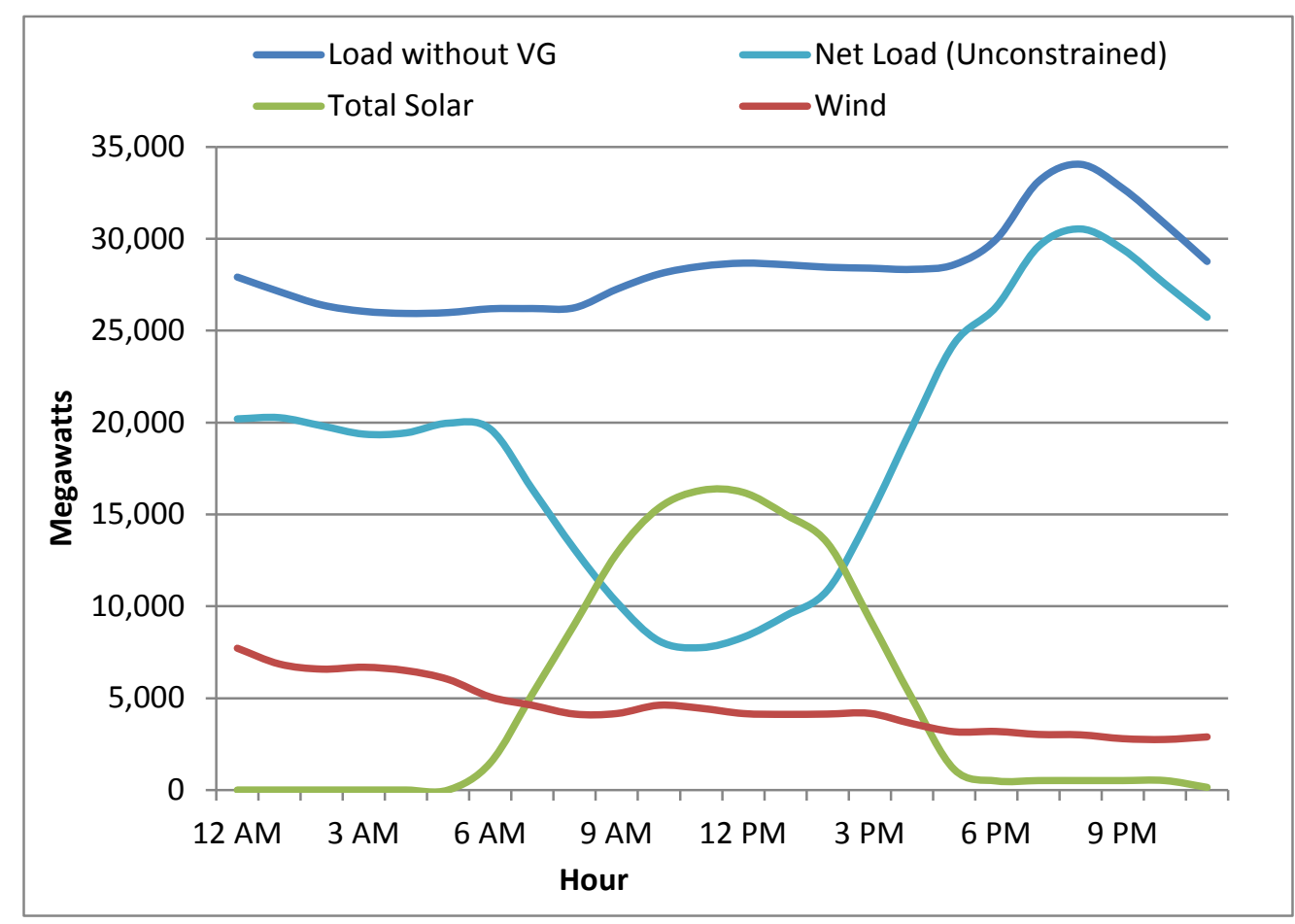

Figure 7. Load, solar, and wind profiles for California on March 29 in a scenario with $11 \%$ annual wind and $11 \%$ annual solar assuming no curtailment

The net load shown in Figure 7 does not consider the operational constraints that actually occur in the dispatch, and these constraints do not allow all renewable energy potentially generated on this day to be used.

The remaining figures in this sequence are from the results of the power system simulation. Figure 8 shows the net load resulting from the VG that can actually be used in the simulated system. In this case, the net load met by conventional generation is not allowed to drop below about 12,600 MW. This represents a California system-wide minimum generation constraint, meaning on-line generators in California - and certain contracted generators outside California- 
cannot reduce output to below this level, considering the individual generator parameters and system limitations described at the beginning of this section. ${ }^{18}$

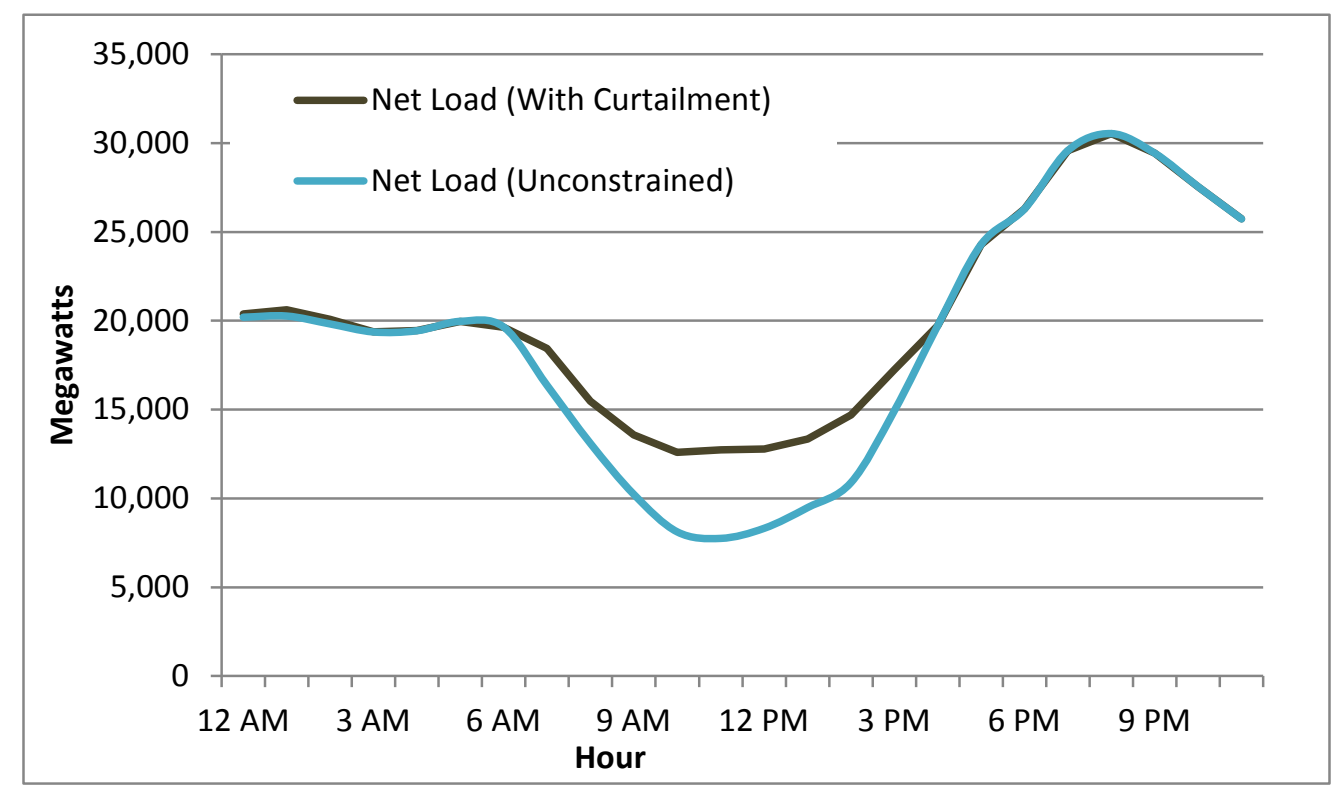

Figure 8. Modeled net load in California on March 29 in a scenario with $11 \%$ annual wind and $11 \%$ annual solar in a system with a $60 \%$ instantaneous penetration constraint

These constraints result in curtailed energy, illustrated in Figure 9, which includes the combined VG potential, the amount of VG used by the system to meet load, as well as the curtailed VG. Curtailment is defined as any VG that cannot be used for any reason. Overall, about 5\% of the potential wind and solar energy on this day is curtailed. However, during most days, higher midday load does not produce a dramatic duck-curve shape and there little or no curtailment. Over the entire year, about $0.2 \%$ of $\mathrm{VG}$ is curtailed.

\footnotetext{
${ }^{18}$ This minimum generation value is already below a CAISO-only estimate of the lowest net load point of about $15,000 \mathrm{MW}$ in the current system (Bouillon 2014). The lower minimum generation point in this analysis results from several factors including greater flexibility from customer-owned cogeneration assumed in the LTPP model. The LTPP model also does not include fixed-scheduling contractual limitations on plant dispatch. Also, Diablo Canyon unit 2 was out for maintenance on this day in the simulation, which removed 1,122 MW of non-dispatchable capacity. The net load in the system is less than 15,000 MW during only 12 hours of the year in this simulation.
} 


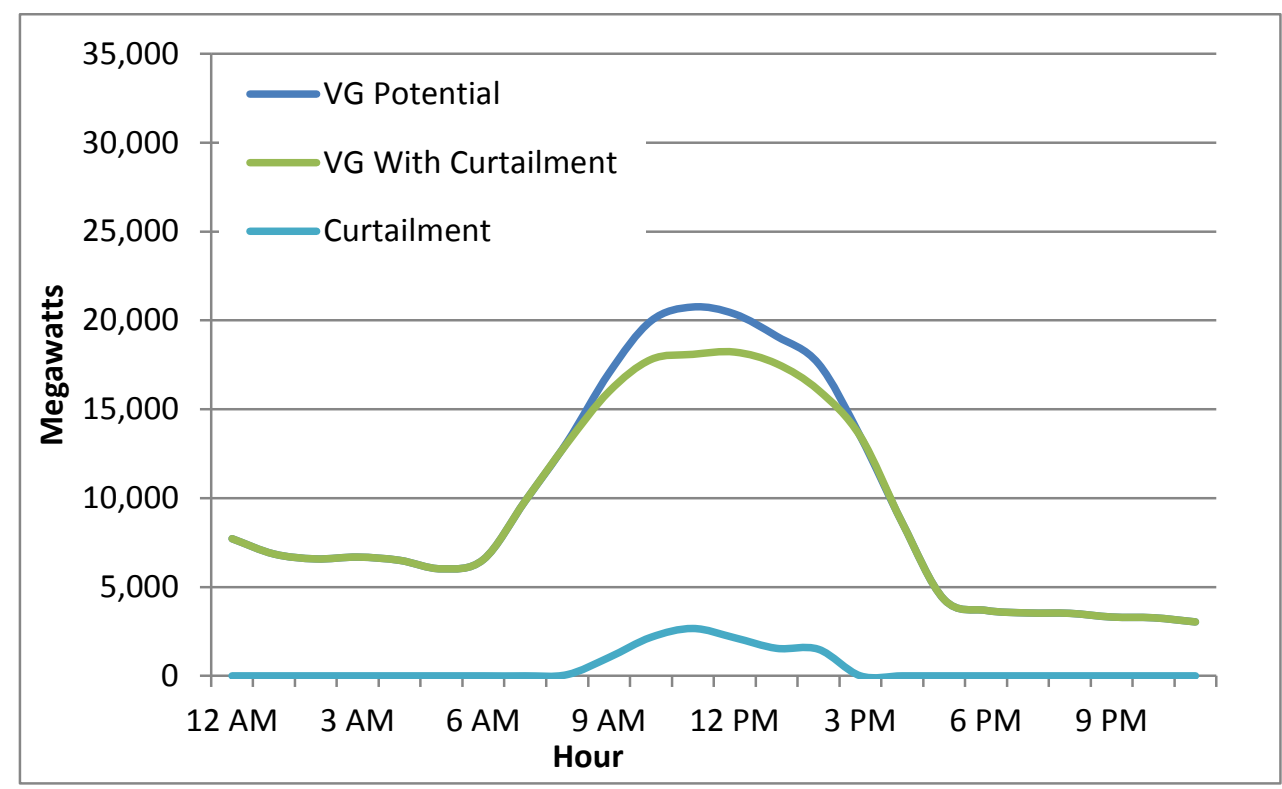

Figure 9. Used and curtailed VG in California on March 29 in a scenario with $11 \%$ annual wind and $11 \%$ annual solar

Figure 10 shows how the $60 \%$ instantaneous penetration limit results in overgeneration and curtailed VG. The bottom curve shows the instantaneous penetration of VG from the model, while the top curve shows the theoretical penetration if all VG could be used. In this case, the VG potential exceeds the $60 \%$ threshold for four hours. ${ }^{19}$ In this scenario, the vast majority (about $95 \%$ ) of all curtailment occurs during periods where the potential VG penetration would exceed $60 \%$. During a few hours of the year there is curtailment at VG penetration levels significantly below $60 \%$, indicating that ramping constraints might force some curtailment. However the total amount of curtailment during these periods is very small compared to the amount created by the $60 \%$ limit. While the average net load ramp rate increases, the existing system appears to be sufficiently flexible address these ramp rates. The normal load (without additional VG) achieves a maximum hourly upward ramp rate of 6,721 $\mathrm{MW} / \mathrm{hr}$ on December $22^{\text {th }}$ at $5 \mathrm{pm}$. In the $11 \%$ annual solar case, only 5 hours of the year demonstrate net load ramp rates that exceed this value, with the maximum net load ramp rate of 7,379 MW/hr. The maximum upward ramp rate on the duck curve day is $3,142 \mathrm{MW} / \mathrm{hr}$. Analysis in later sections evaluates the relationship between a lower penetration limit and possible ramp rate constraints at higher PV penetration.

\footnotetext{
${ }^{19}$ The actual penetration of VG is slightly less than $60 \%$ because the constraint does not consider a small amount of schedulable load within the model.
} 


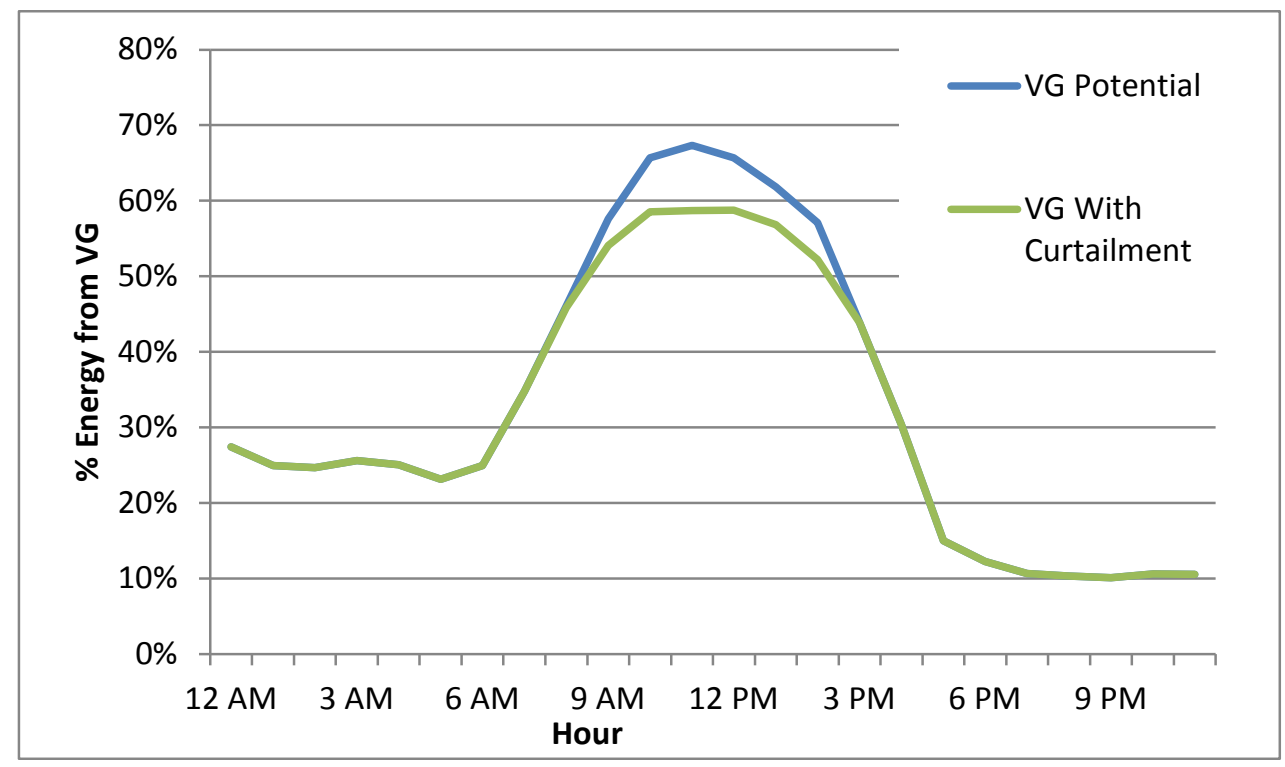

Figure 10. Instantaneous penetration of VG on March 29 with and without curtailment in a scenario with $11 \%$ annual wind and $11 \%$ annual solar

Of note in these results is the use of existing pumped storage in the California system, which represents a total of 2,518 MW of generation capacity ${ }^{20}$ including 2,264 MW of schedulable pumping load that can be used to increase total demand during periods of high solar output.

Figure 11 shows the simulated storage pumping load that occurs, and how storage results in an increase in VG used. As noted previously, because this conservative base case considers grid conditions that approximate those of 2015, this simulation does not consider the 1,325 MW of additional storage that will be deployed as part of the California storage mandates, which is evaluated in later sections.

\footnotetext{
${ }^{20}$ These values are for the four existing California pumped storage plants in TEPPC common case (Castaic, Eastwood, Helms, and Lake Hodges). The CAISO LTPP model has a combined capacity of 2,728 MW for these four plants.
} 


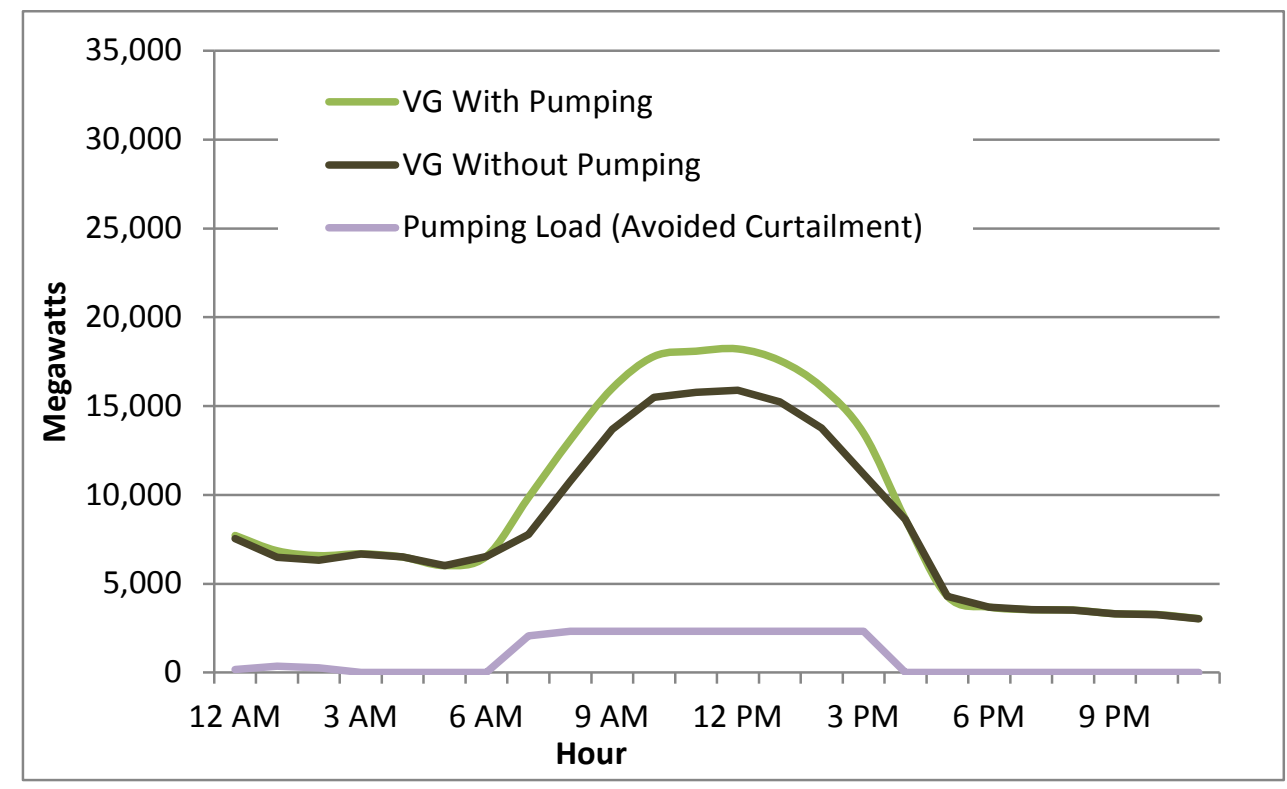

Figure 11. Increase in VG use resulting from schedulable pumped storage in a scenario with $11 \%$ annual wind and $11 \%$ annual solar

On most days of the year, significant additions of PV are possible without causing significant curtailment. Figure 12 duplicates Figure 7, but for July 27, the day with the highest demand (note the scale change on the y-axis due to the significant increase in demand). On this day, there is no VG curtailment, and instantaneous penetration is well below the $60 \%$ threshold, as illustrated in Figure 13.

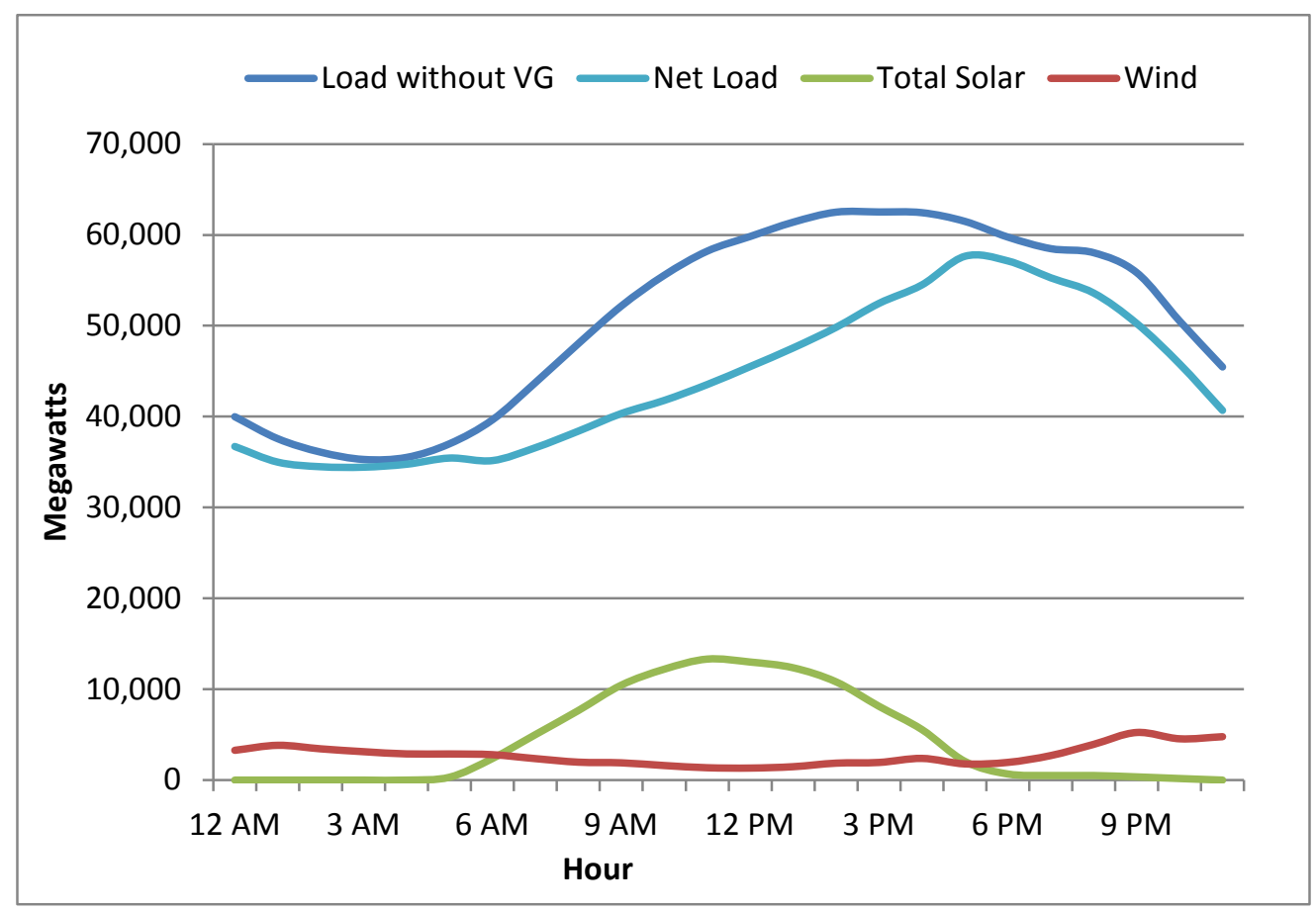

Figure 12. Load, solar, and wind profiles for California on July 27 in a scenario with $11 \%$ annual wind and $11 \%$ annual solar 


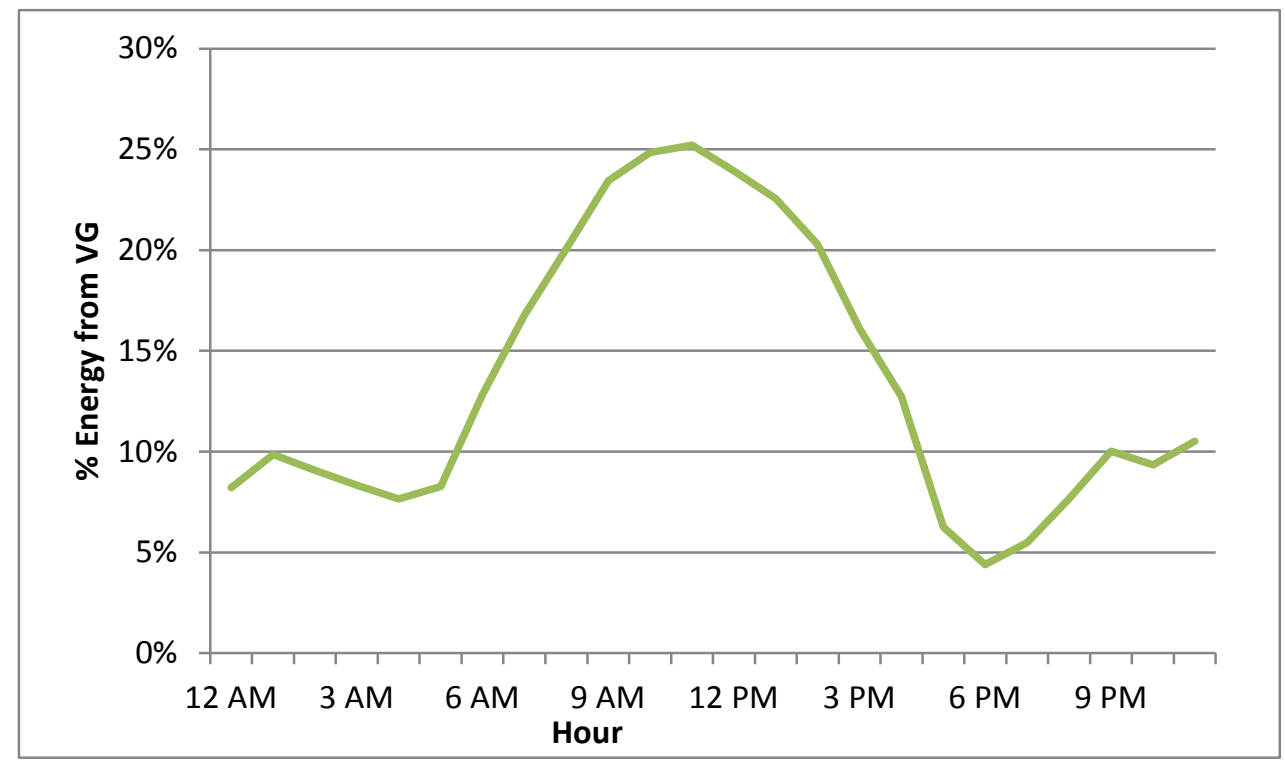

Figure 13. Instantaneous penetration of VG in California on July 27 in a scenario with $11 \%$ annual wind and $11 \%$ annual solar

The duck chart figures show the challenge of additional PV penetration without increasing system flexibility. Adding PV to help reduce the use of peaking capacity on July 27 also produces more energy on March 29. Without flexibility changes that will allow additional units to reduce output or be de-committed, only a relatively small amount of additional PV generation can be accommodated on March 29 (during the shoulder periods in the morning and evening). And as more PV is added, there will be a greater number of days with associated PV curtailment.

Figures 14-16 show the progression of the duck curve and associated overgeneration as additional PV is added. Figure 14 shows what the net load would be on March 29 without curtailment in both the base case illustrated previously and a case where we add sufficient PV to meet $15 \%$ of total annual demand (pre curtailment). In this case, the pre-curtailment net load drops significantly, to below 5,000 MW. 


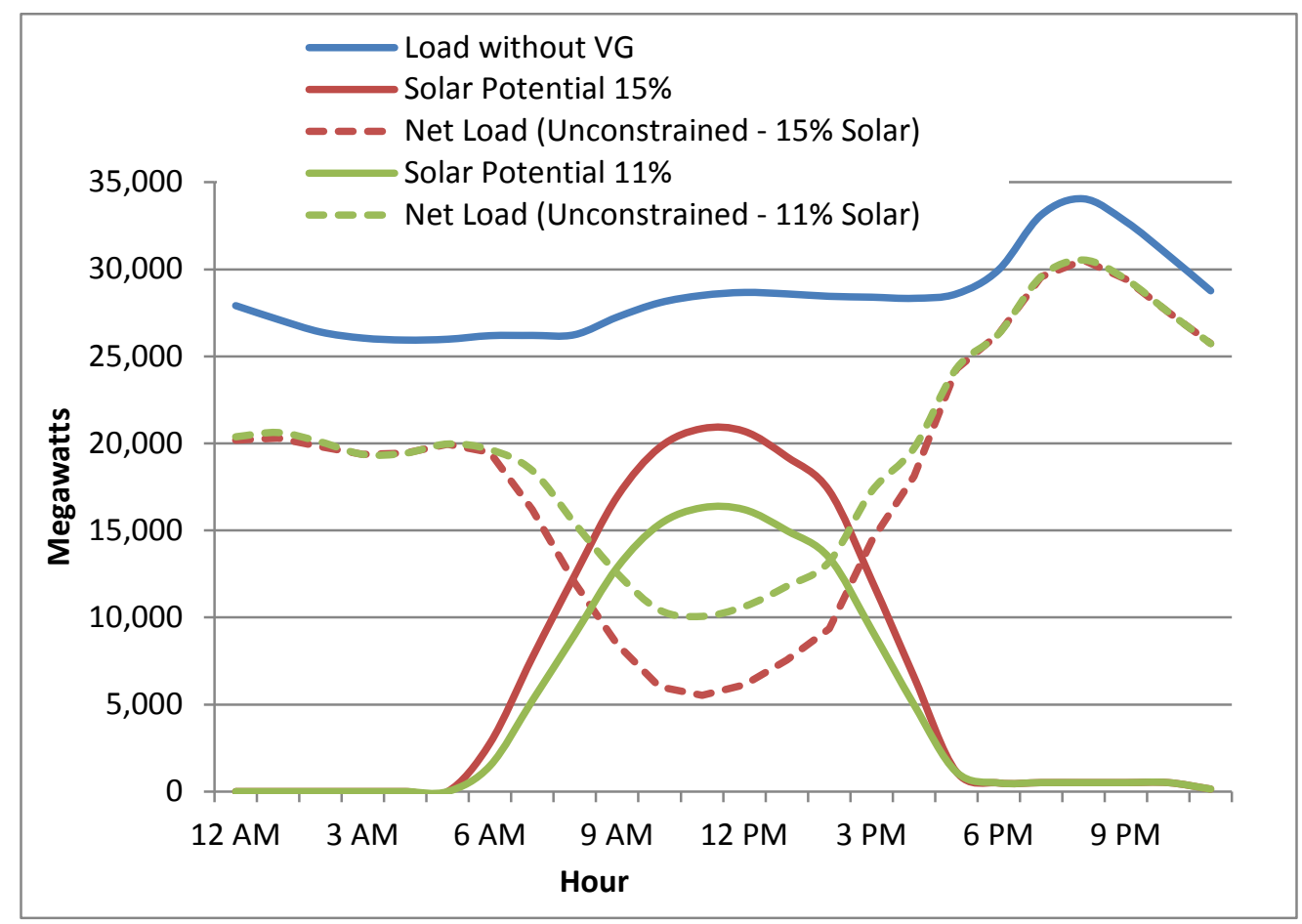

Figure 14. Load in California and VG Profiles on March 29 in a scenario with $11 \%$ and $15 \%$ annual solar assuming no curtailment

While Figure 14 shows the belly of the duck growing as more solar as added, the net load changes very little at the higher PV penetration due to the $60 \%$ penetration constraint in the base case. Figure 15 shows how the belly of the duck curve is prevented from growth due to this constraint, and very little additional PV can be used in the simulated system on this day. Figure 16 shows the hourly curtailment and the used PV in the two cases. At the lower penetration, nearly all the PV (95\%) is used on this day, but in the case with additional PV, most of this additional PV is curtailed. Only a small amount of PV in the morning and late afternoon is actually useful, and the total curtailment on this day increases from $5 \%$ to about $13 \%$. However, the marginal curtailment on this day, or curtailment of the additional PV added to the system between the two scenarios is about $65 \%$. This illustrates the importance of differentiating the total curtailment and incremental, or marginal curtailment of PV. On an annual basis, the total curtailment increases from $0.2 \%$ to $0.9 \%$, while the marginal curtailment is $5.5 \%$. 


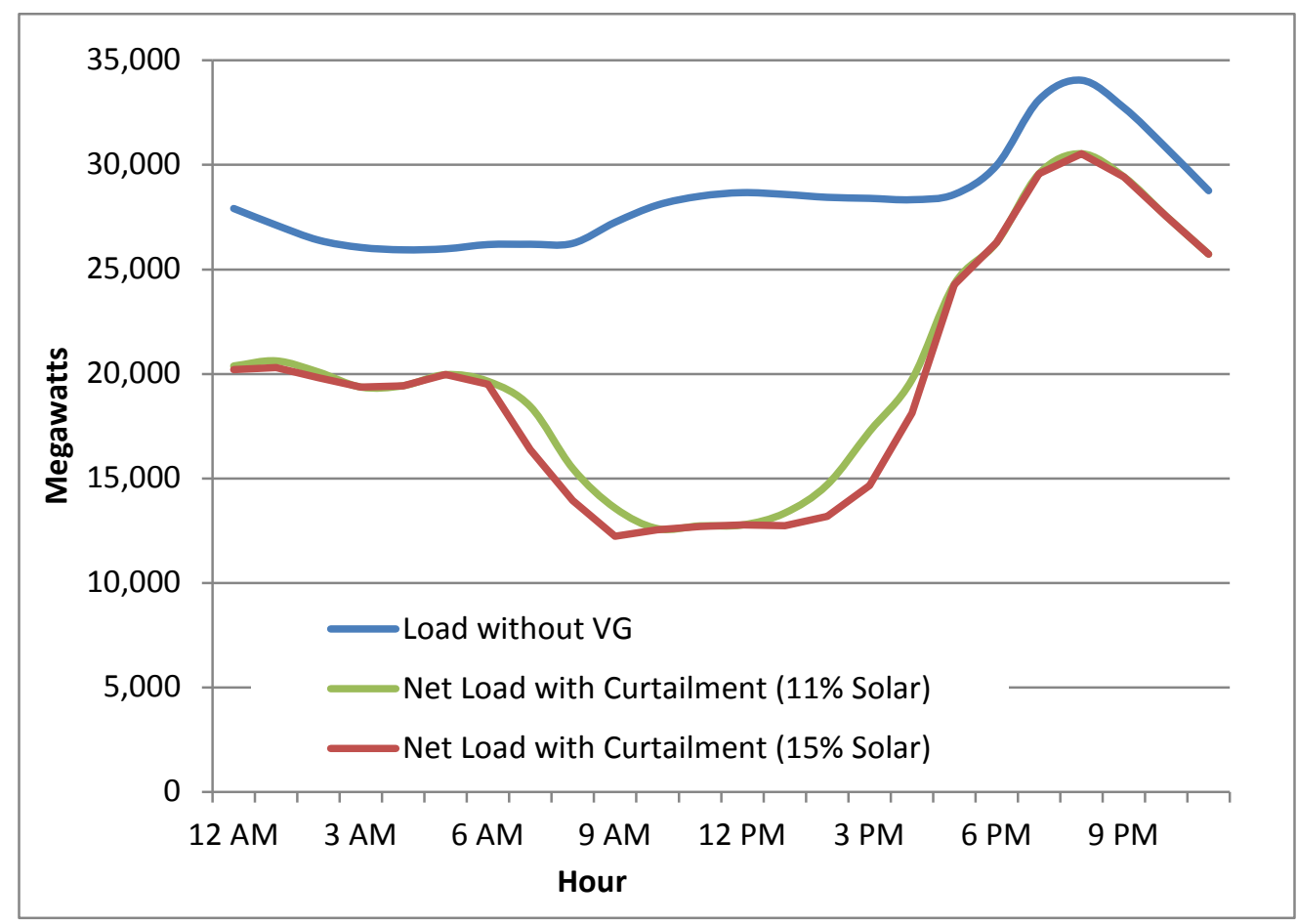

Figure 15. Net load on March 29 in a scenario with $11 \%$ and $15 \%$ annual solar considering operational constraints

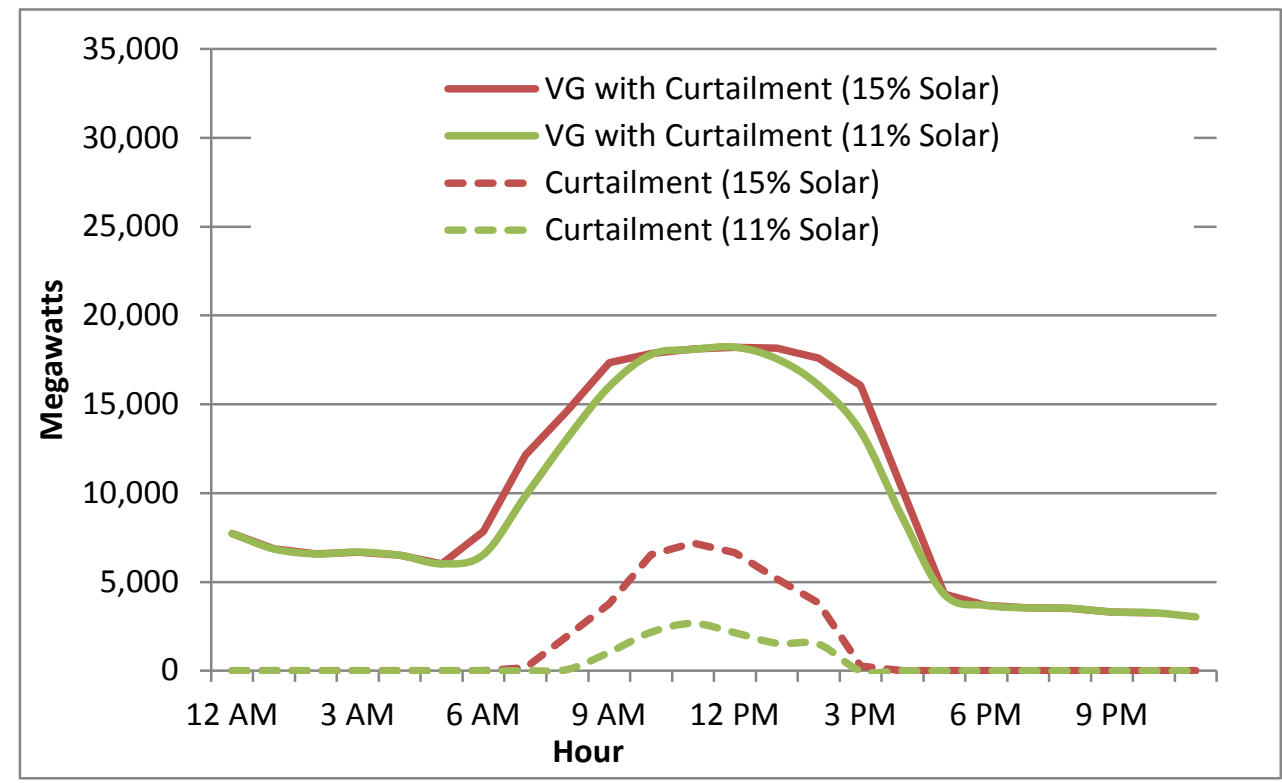

Figure 16. Usable and curtailed VG on March 29 in a scenario with $11 \%$ and $15 \%$ potential annual solar 
As even more PV is added to the system, more days acquire the duck shape, and overgeneration increases. Figure 17 illustrates the resulting fraction of variable generation curtailment due to overgeneration as a function of penetration. The bottom $\mathrm{x}$-axis shows the total penetration of solar energy sources (PV plus CSP), while the top x-axis shows the penetration eligible renewable resources (solar plus wind, geothermal, biomass, and small hydro). Only PV is added and the overall penetration is defined as the annual contribution of renewable energy to the total energy demand in California, ${ }^{21}$ after removing curtailed energy.

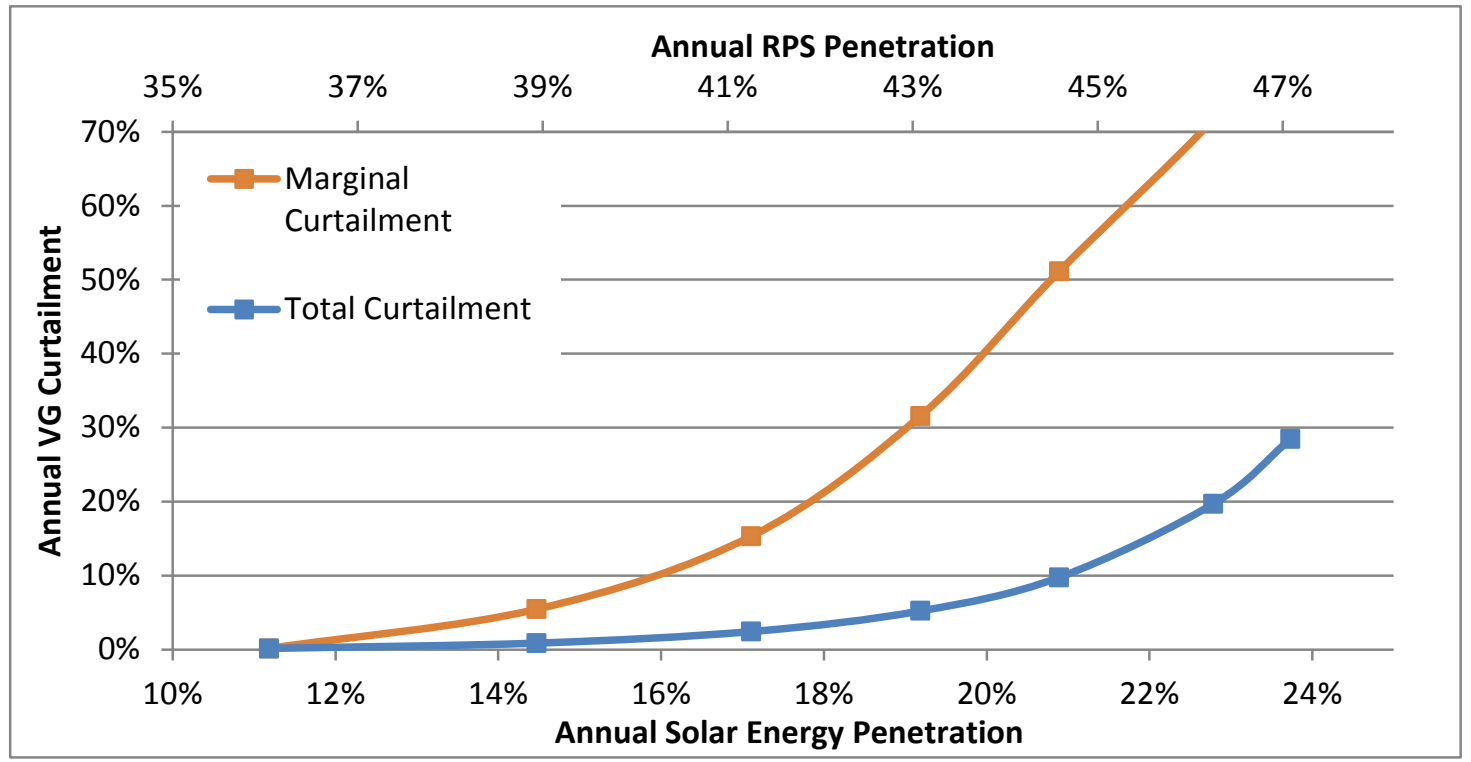

Figure 17. Marginal and average curtailment due to overgeneration under increasing penetration of $\mathrm{PV}$ in California with a $60 \%$ instantaneous penetration limit

The rapid increase in marginal curtailment rates as a function of PV penetration is a significant limitation for PV to remain competitive with other sources of low-carbon energy once it achieves a certain penetration (in this case perhaps $15 \%-20 \%$ of annual demand). This challenge can be observed by examining the impact of curtailment on the levelized cost of energy (LCOE) of PV. As curtailment increases, and capacity factors decrease, the LCOE increases. This is illustrated in Figure 18, which provides PV LCOE as a function of penetration for the base case scenario. In this figure, the PV cost is based on the DOE solar program goal of an LCOE equal to six cents per kilowatt-hour. This goal is largely dependent on being able to actually use all the energy available from PV and on minimizing curtailment.

${ }^{21}$ Where the total demand is equal to the consumer demand plus storage losses associated with pumped hydro 


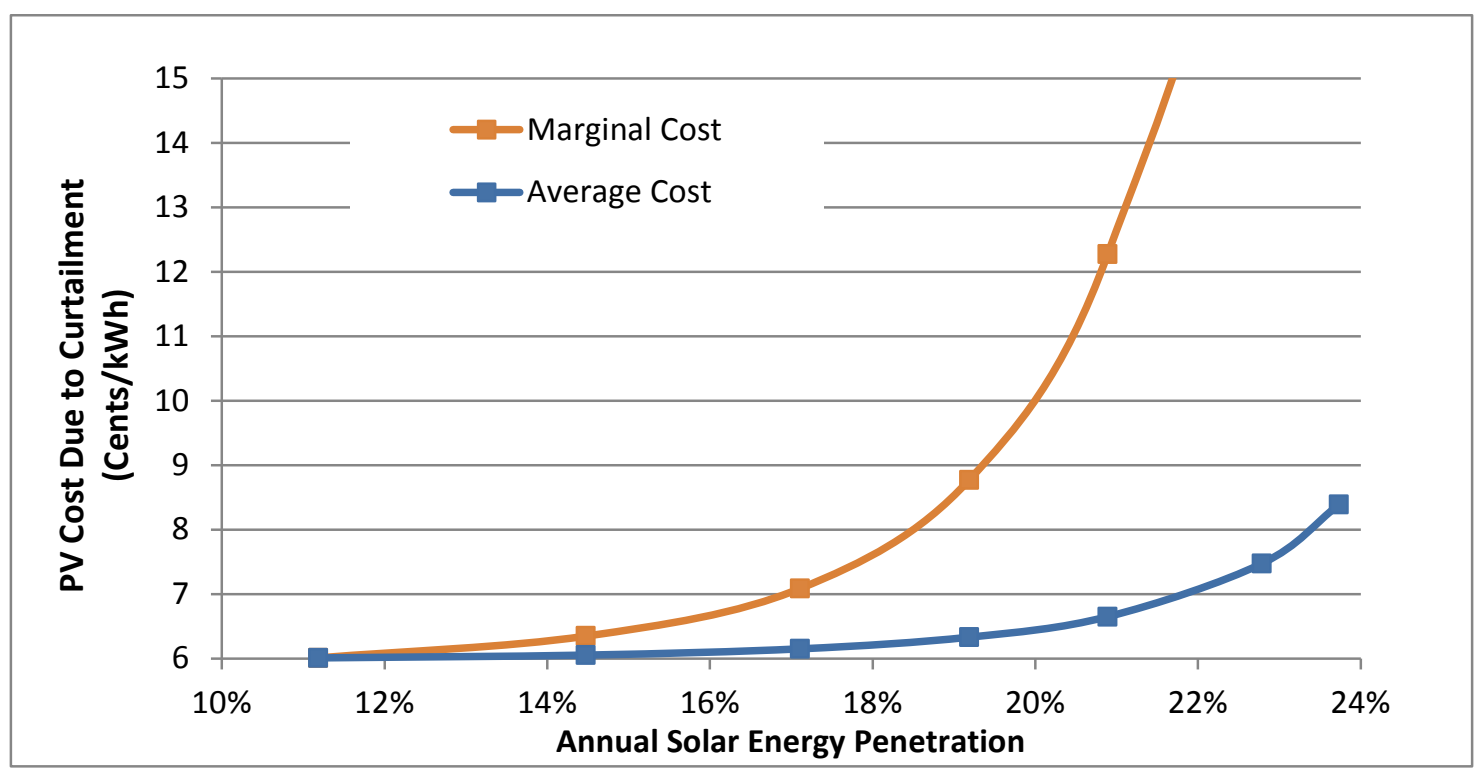

Figure 18. Marginal and average PV LCOE (based on SunShot goals) due to overgeneration under increasing penetration of PV in California with a $60 \%$ instantaneous penetration limit

Figure 18 shows the importance of examining marginal curtailment rates. While average rates can remain relatively low, marginal rates determine the cost and value of adding the next unit of solar to the grid. Actual investment decisions may be driven by these marginal values, with actual allocation of curtailment driven by a variety of factors, including local grid conditions, the underlying contractual agreements with suppliers, production tax credits, and other regulatory issues. It should be noted that in Figure 18 all incremental curtailments of non-zero cost renewable energy resources (CSP, wind, hydro, and geothermal) were assigned to PV. For example, if at the lowest penetration of PV there is no curtailment of wind, and when PV is added wind is curtailed, this wind curtailment is actually assigned to PV for accounting purposes.

The very high marginal curtailment rates of PV observed in Figure 17 would likely limit contribution from solar without changing system operation to accommodate variable generation resources. Examination of the duck curve provides insights into how improved flexibility can both accommodate and change the net load shape and increase penetration of solar energy resources. 


\section{Enabling Greater Solar Penetration: Flatten or Fatten the Duck?}

Accommodating greater amounts of PV will likely require multiple approaches to increasing the overall flexibility of the power system. Previous work by the CAISO (Bouillon 2014) and other groups (listed in Section 3) suggest many individual approaches, but these can be summarized by two more general approaches, which we illustrate below as fattening the duck and flattening the duck.

Fattening the duck represents all approaches that increase the flexibility of the grid and allow greater instantaneous penetration of variable generation resources. Typically, this means (1) changing operational practices to allow more frequent cycling, unit starts and stops, and (2) minimizing the amount of thermal units held at part load by improving accuracy of VG forecasts and not holding excessive reserves. This also means allowing VG to provide operating reserves and other services that stabilize system frequency (Gevorgian et al. 2015). These changes can reduce the overall system-wide minimum generation requirement, and they allow the natural belly shape of the duck to grow larger and provide a greater fraction of the normal load during periods of high solar output.

Figure 19 illustrates the change in minimum generation requirements that would be needed to eliminate curtailment on our lowest net load day in the $15 \%$ solar penetration scenario. The net load in this figure is from the constrained system illustrated in the previous section (Figure 15). In this case, the system's minimum generation point of about $12,600 \mathrm{MW}$ results in significant curtailment. If the system were able to operate at a lower minimum generation level (about 5,400 MW), curtailment would be eliminated. 


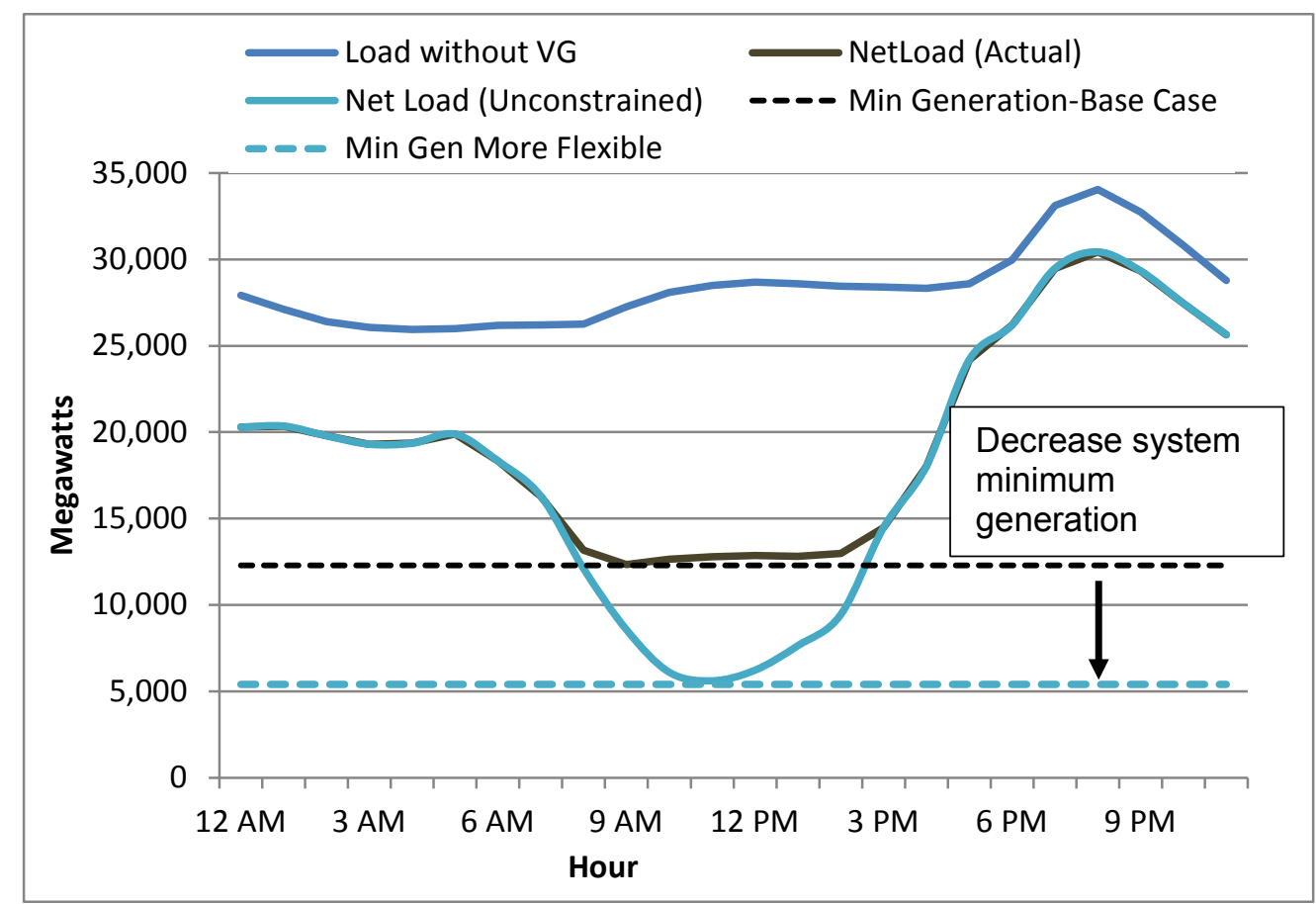

Figure 19. Accommodation of increased penetration of $\mathrm{PV}$ by reducing system minimum generation requirements and fattening the duck

Alternatively, flattening the duck acts to shrink the belly shape by shifting supply/demand patterns to allow solar energy to meet parts of the load that would not normally be provided in the middle of the day. This includes either shifting load via responsive demand or shifting supply by the use of energy storage (Lazar 2014).

Figure 20 illustrates the amount of load shifting that would be required to eliminate curtailment. In this example, we keep the $12,600 \mathrm{MW}$ minimum generation level associated with the $60 \%$ instantaneous penetration limit. We add load (from shiftable demand or storage) with timing and amounts that exactly match curtailment of PV. As much as 7,200 MW of additional demand or storage charging would be required to eliminate all curtailment in this case. The impact of load shifting/storage is shown on both the normal (no VG) load (the top curve) as well as the net load with VG. On the normal load, additional demand produces a "hump" on the back of duck. This stored energy will be used later (or demand later in the day will be shifted earlier), reducing demand in the evening (represented by the flat line where the load has been reduced). The impact on the net load is to increase the net demand to the minimum generation level, with the added benefit of reducing peak demand in the late evening. 


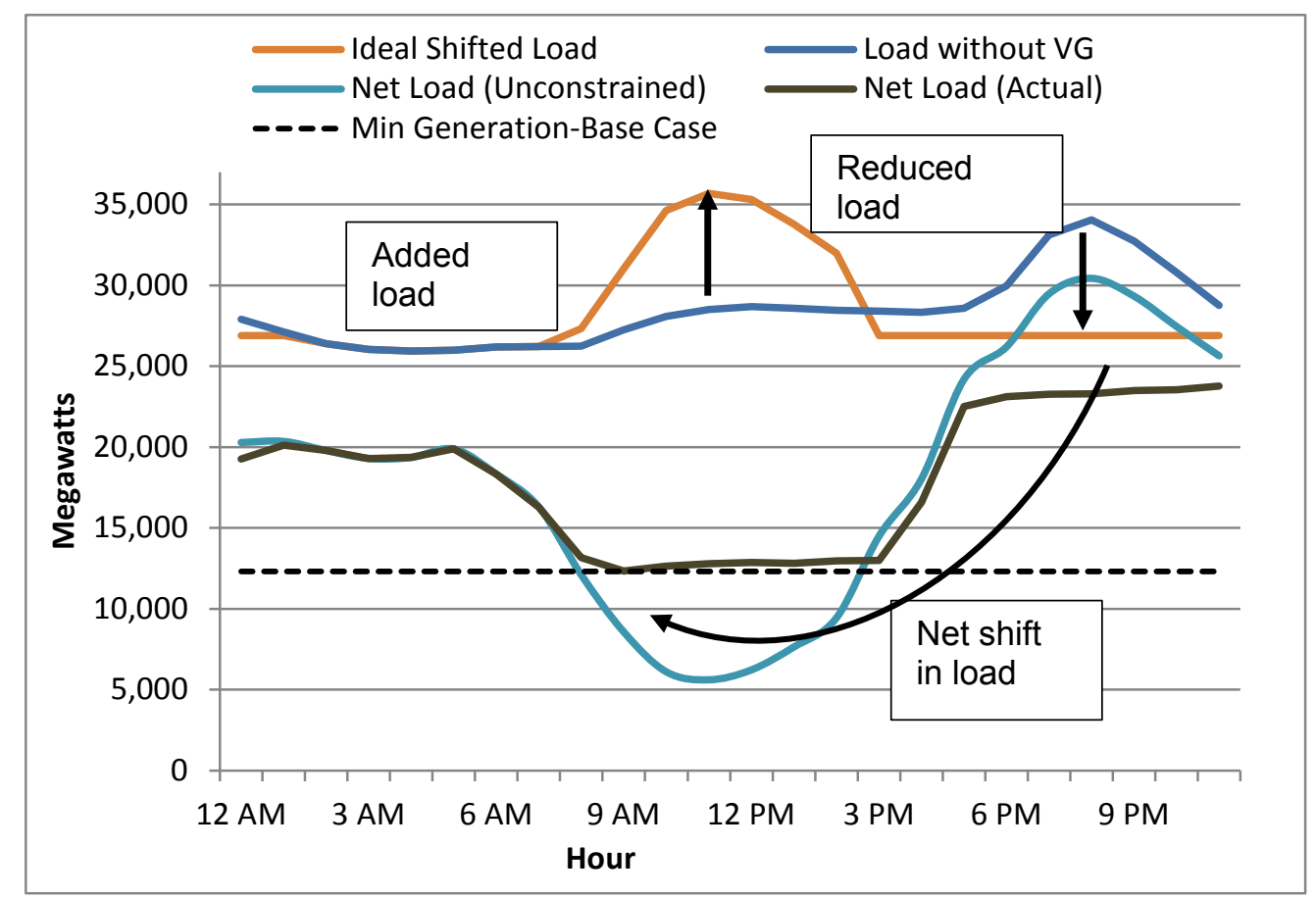

Figure 20. Accommodation of increased penetration of PV by flattening the duck (increasing mid-day demand)

Increased penetration of PV can occur by applying either approach individually, but the greatest impact will occur when the approaches are applied collectively. 


\section{The Impact of Improved System Flexibility}

\section{Increasing Instantaneous Penetration and the Impacts of the California Storage Mandate}

The base case analyzed in Section 5 does not consider several grid changes that will likely occur by 2020 that will help reduce the impact of solar generation on grid operations. Among these changes is the deployment of new energy storage. In October 2013, the California Public Utilities Commission (CPUC) finalized Decision 13-10-040, which adopts procurement targets and requirements for 1,325 MW of "viable and cost-effective" energy storage systems by 2020, as directed by the California State Legislature in 2010 (CPUC 2010; CPUC 2013).

This new storage can help accommodate increased use of VG by shifting load and flattening the duck. We consider the addition of 1,290 MW of storage, following the modeling assumptions of the TEPPC 2024 database. $^{22}$ The size and characteristics roughly follow CPUC R.13-12-010 and include $550 \mathrm{MW}$ with two-hour discharge duration, $520 \mathrm{MW}$ with four-hour discharge duration, and $220 \mathrm{MW}$ with six-hour discharge duration. The devices are assumed to have $83 \%$ round-trip efficiency and are distributed among the three California investor-owned utility zones in accordance with the storage mandate. We assume all of the storage added is optimized by the system operator to minimize the overall cost of system operation and can provide multiple services including provision of reserves. ${ }^{23}$ This is a critical assumption, and it would require optimization either (1) directly by a system operator in the case of utility-scale storage or (2) indirectly through real-time pricing or other mechanisms that would optimize behind-the-meter storage. Figure 21 illustrates how this additional storage shifts load to flatten the duck and reduce curtailment. This figure shows the normal load from the $15 \%$ PV case and load with the additional storage. The resulting curtailment is also shown, and is compared to the case without the added storage.

\footnotetext{
${ }^{22}$ The 40-MW Lake Hodges plant is eligible for the storage mandate, and it existed in the base case, so the additional storage is less than the $1,325-\mathrm{MW}$ requirement.

${ }^{23}$ This is a deviation from the current assumptions in the LTPP model, which assumes a mix of transmission, distribution, and customer sited storage, of which only a fraction can provide reserves (Liu 2014a).
} 


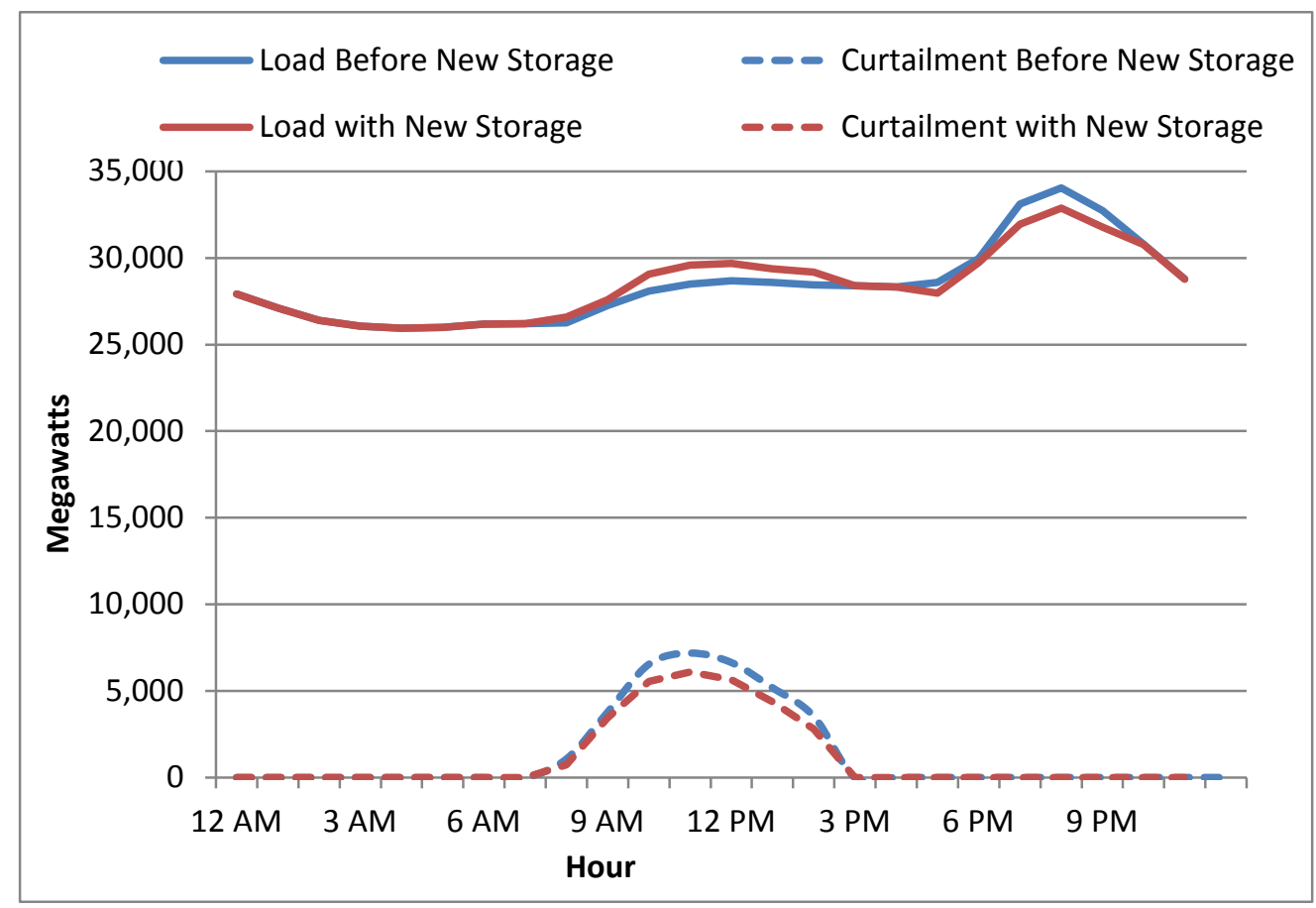

Figure 21. Impact of flattening the duck on March 29 with 1,285 MW of added storage in a scenario with $15 \%$ annual solar

The amount of avoided curtailment in Figure 21 is relatively modest, but it does not consider a potentially even greater benefit of distributed storage by provision of grid flexibility services. By providing these services (including grid stability), storage can help reduce the need to run partially loaded thermal generation to provide reserves.

The previous section shows the significant impact of the $60 \%$ instantaneous penetration limit, which creates the flat belly on the duck curve and results in significant overgeneration. While we impose the $60 \%$ limit in our base case, the CAISO LTPP model imposes a $25 \%$ local generation limit, which requires $25 \%$ of local load in all hours to be met by conventional generators (which we also include in our base case in the previous section). Renewables, demand response, and storage are ineligible in the CAISO model to meet this requirement. The motivation for this limit is described as:

The constraint is necessary for the balancing authority to comply with the NERC control performance standards. A balancing authority must have at least $25 \%$ of its internal generation on-line with adequate available capacity for dispatch or risk non-compliance. Within the CAISO's footprint, a contingency that results in the tripping of Path 26 would separate the north from the south. Without a minimum amount of generation in southern California, there is a risk that the CAISO could completely lose the load if Path 26 were to open. ${ }^{24}$

${ }^{24}$ Liu 2014a 
The common theme behind these concerns is the ability of a system operator to maintain system stability, including voltage stability and frequency stability. ${ }^{25}$ While there is little direct experience in operating grids in the United States with extremely high levels of instantaneous VG penetration, ${ }^{26}$ studies suggest a variety of approaches to maintaining system stability under increased VG penetration. One example is Phase 3 of the Western Wind and Solar Integration Study (WWSIS-3) (Miller et al. 2014), which examined frequency and transient stability at instantaneous VG penetrations of up to $53 \%$ across the Western Interconnection and $62 \%$ in California. The study simulated the frequency declines after severe disturbances, and found that at the levels of penetration simulated, the system was able to maintain enough primary frequency response to avoid under-frequency load shedding (blackouts). The study also concluded that the use of active power controls in wind turbines and PV could improve frequency response, which could allow greater instantaneous penetration of VG. Currently available wind turbines are now being deployed that can provide active power control, including both synthetic inertia and primary frequency response. Wind turbines can draw stored energy from the rotor to help arrest a frequency decline, or they can be operated at reduced output during periods of high VG penetration to provide primary frequency (governor) response. PV can also provide these services, although both require curtailment.

Fast-responding energy storage, such as batteries and flywheels, can provide rapid response to grid events. The amount of new storage in the California storage mandate significantly exceeds the WWSIS-3 estimated frequency response obligation for California, and WWSIS-3 found that a relatively small amount of storage (less than that in the California storage mandate) could provide significant benefits across the entire Western Interconnection.

As active power controls become more common on renewable generators, and if the system operator has greater control over the new storage being installed in California, these resources could be employed to replace the services now provided by conventional thermal resources.

To demonstrate how commercially available grid flexibility options can effectively fatten the duck, we consider a case where control of distributed resources allows for increased instantaneous penetration of VG. We also allow curtailed wind and solar to provide upward regulation, contingency, and flexibility reserves. While this provides a system benefit, we do not count curtailment that provides upward reserves as "used" energy. However this has a small impact as curtailed VG typically provides less than $4 \%$ of the total reserve requirement (During hours of large curtailment, there is typically a significant amount of partially loaded hydro or thermal plants that can provide upward reserves.)

\footnotetext{
${ }^{25}$ A summary of stability issues is provided by Kundur et al. (2004). They give the following definitions: "Voltage stability refers to the ability of a power system to maintain steady voltages at all buses in the system after being subjected to a disturbance from a given initial operating condition" and "Frequency stability refers to the ability of a power system to maintain steady frequency following a severe system upset resulting in a significant imbalance between generation and load."

${ }^{26}$ In October 2014, the Xcel service territory in Colorado provided $61.1 \%$ of demand with wind, which was partially enabled by utilizing wind to provide regulating reserves. However, because this system is connected to the larger Western Interconnection, it does not provide a realistic example of high-penetration of non-synchronous generation across a large balancing area or interconnection.
} 
Figure 22 shows an example of a fatter duck that results from increasing the allowable instantaneous penetration from $60 \%$ in the base case to $80 \%$ (with no local generation requirement). The top curve shows the net load in the $15 \%$ base solar case (the same curve as shown in Figure 15). The bottom curve shows the impact of increasing maximum penetration to $80 \%$, which substantially reduces curtailment on this day.

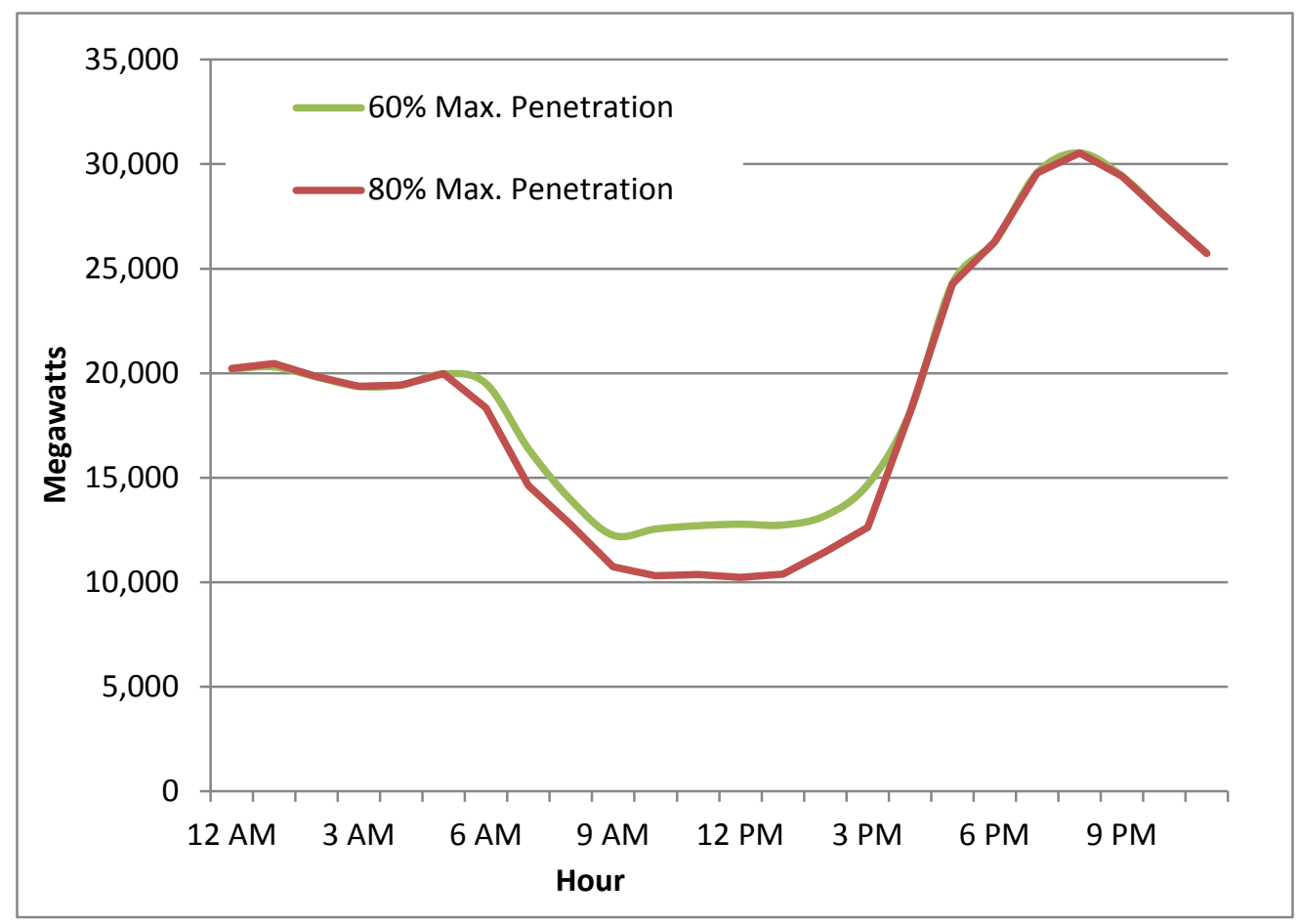

Figure 22. Net load on March 29 in a scenario with $15 \%$ annual solar increasing the maximum penetration of VG to $60 \%$ to $80 \%$

The corresponding curtailment curves are provided in Figure 23. In this case, the curtailment of PV has been substantially reduced from about $13 \%$ on this day to about $7 \%$. 


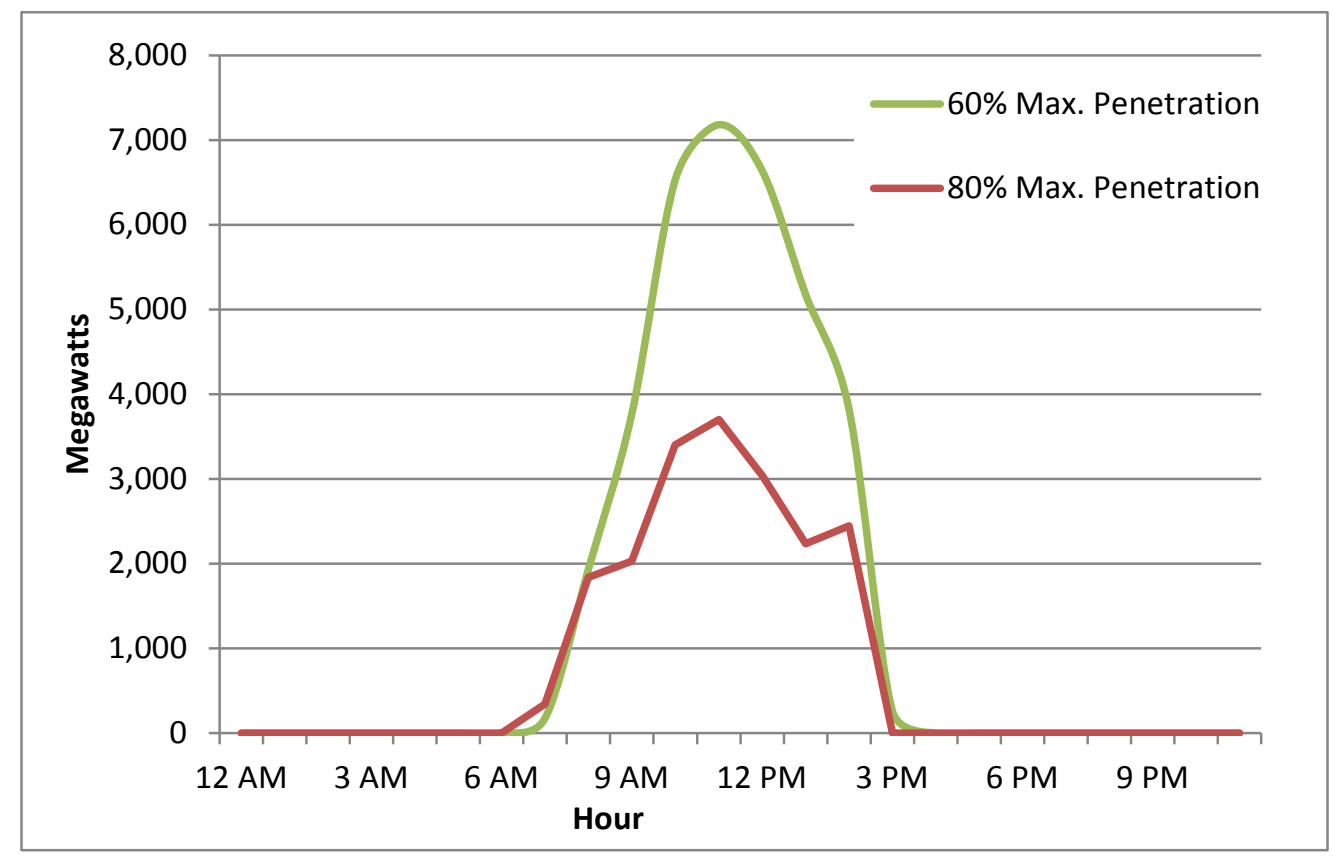

Figure 23. VG curtailment on March 29 in a scenario with $15 \%$ annual solar increasing the maximum penetration of $V G$ to $60 \%$ to $80 \%$ and removing the local generation requirement

While curtailment has been reduced, it has not been completely eliminated due to other constraints on the system. The 10,000 MW net load in Figure 22 is close to the minimum output of "must-run" capacity in the system. Overall, the model identifies about 8,000 to 9,000 MW of minimum generation from nuclear, geothermal, hydro, biomass, and gas-fired combined heat and power (CHP) units. $^{27}$

Overall, these changes to grid operation reduce curtailment and allow greater penetration of VG. Figure 24 compares the impact of replacing the original base case (including the $60 \%$ instantaneous limit and the $25 \%$ local generation constraint) with an overall $80 \%$ instantaneous VG penetration constraint. It is important to emphasize that this assumption requires the system operators to have greater visibility and control of multiple distributed resources, including both PV and storage. These distributed resources will likely be needed to perform many functions currently met by conventional generation resources, with appropriate controls and market mechanisms put in place to compensate owners for providing these services.

Compared to the base case, the curtailment curves are shifted to the right by about 8 percentage points, meaning greater energy penetration from solar can be achieved at the same level of curtailment. In this case, a solar penetration of $25 \%$ is achieved with a marginal curtailment rate of about $20 \%$, with the total RPS level approaching $50 \%$.

\footnotetext{
${ }^{27}$ As noted previously, this low level is made possible in part by the fact that one unit of Diablo Canyon nuclear units was out for maintenance on this simulated day.
} 


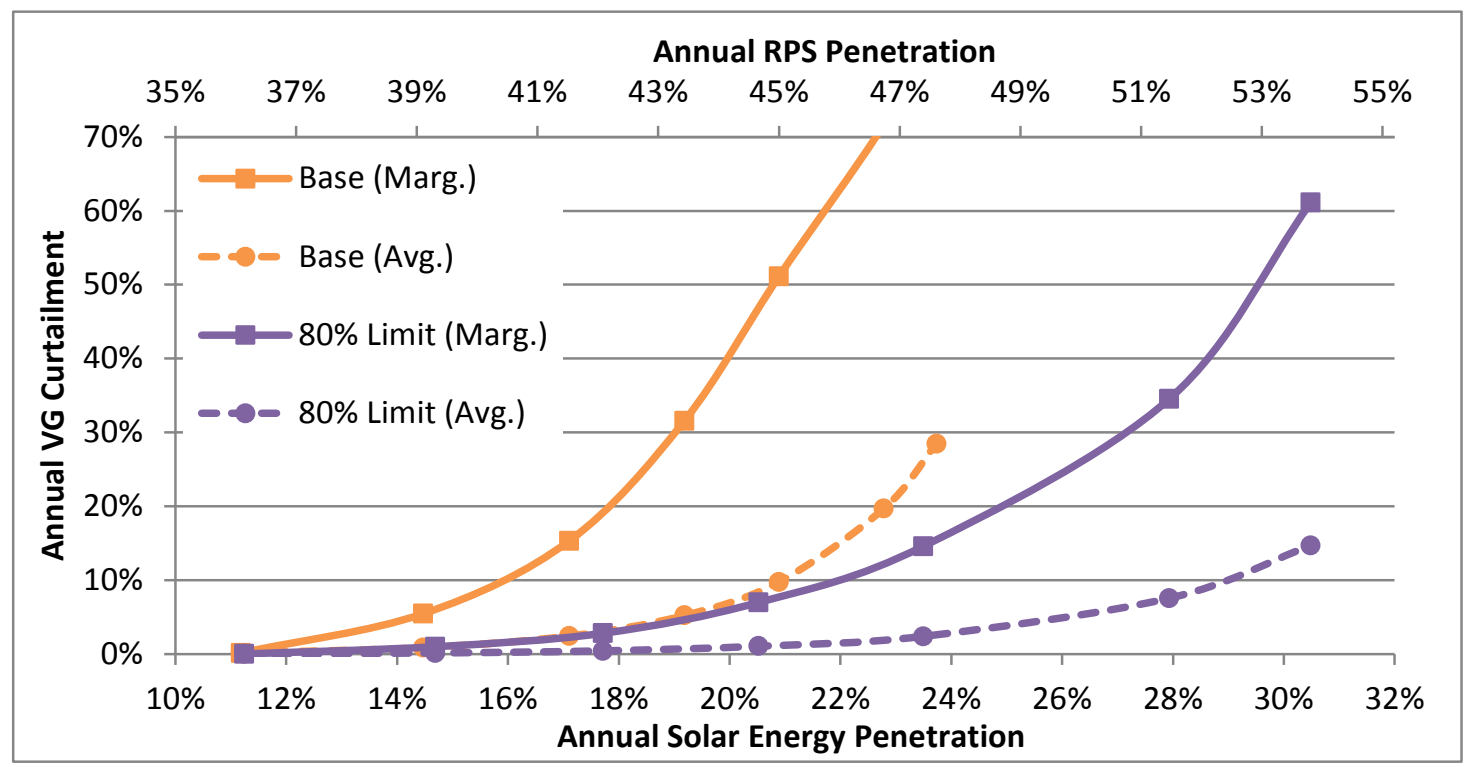

Figure 24. Marginal and average annual curtailment due to overgeneration under increasing penetration of PV in California after adding mandated storage, removing local generation constraint, and increasing maximum instantaneous VG penetration to $80 \%$

\section{Engaging Further Demand Response}

The solutions in the previous section fatten and flatten the duck by applying commercially available control technologies to local generation and storage resource. However, the base cases assume a very small amount of responsive demand that could allow greater PV penetration. As with energy storage, demand response (DR) can both flatten the duck (by shifting load) and fatten the duck (by providing grid services that reduce need to operate conventional plants at part load). Fattening the duck with DR will require provision of services not typically provided by loads. While demand shifting can occur through market-based incentives (e.g., time-varying prices), using DR to allow for increased VG penetration will likely require DR to provide grid stability services (e.g., primary frequency response). This will require loads to sense system frequency and automatically reduce load during low frequency events. ${ }^{28}$ This incurs both an implementation cost and any costs associated with paying customers when load is curtailed.

To consider the possibility of how responsive demand could aid in PV integration, we consider two steps similar to the previous case. First, we assume a greater fraction of load (up to about $11 \%$ of instantaneous demand) can be incentivized to shift demand to times of lower energy prices (corresponding to low net demand). ${ }^{29}$ Second, we increase the VG instantaneous penetration limit to $90 \%$. This assumption reflects the possibility that directly controllable responsive demand can provide the system operator with increased flexibility including frequency stability measures such as primary frequency response.

\footnotetext{
${ }^{28}$ An example of an existing program that uses frequency-responsive loads is the ERCOT "Non-Controllable Load Resource" that provides Responsive Reserve Service. This program pays loads to reduce output automatically when the frequency drops below a certain threshold (ERCOT 2014).

${ }^{29}$ This and other changes to system operation will likely require new market mechanisms. Hogan and Paulos (2014) discuss several of these.
} 
Figure 25 illustrates the impact of the added demand response on net load shape in the $24 \%$ potential solar case. Figure 25a shows the result for the duck curve day (March 29), while Figure $25 \mathrm{~b}$ shows the result for the peak load day (July 27). The scales are the same for comparison. The impact on March 29 is very small due to the assumptions regarding the amount of shiftable demand, which is based largely on heating and cooling demand. The basis for this is discussed in Brinkman et al. (2015). On March 29, there is little need for either cooling or heating in the middle of the day, meaning there is low potential for demand shifting on this day based on the model assumptions. The impact on July 27 is more significant, and while DR adds significant economic benefit from load shifting, no curtailment occurs on this day.

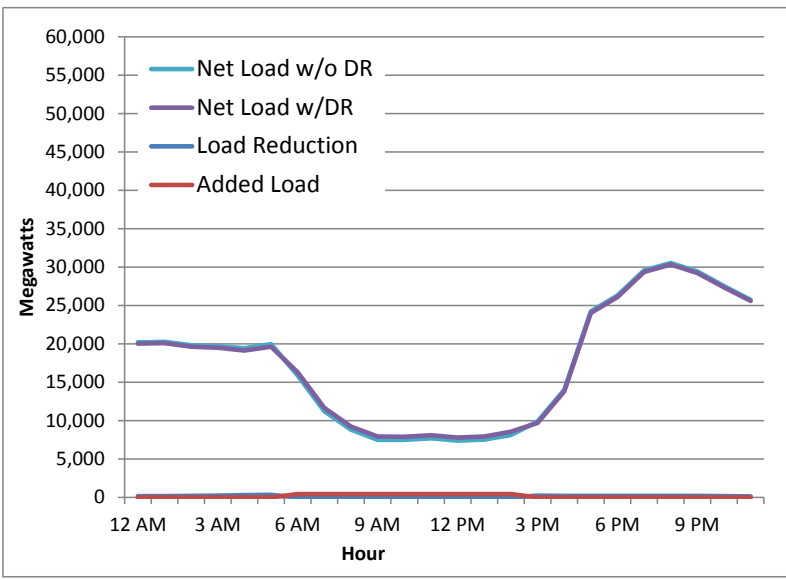

(a) March 29

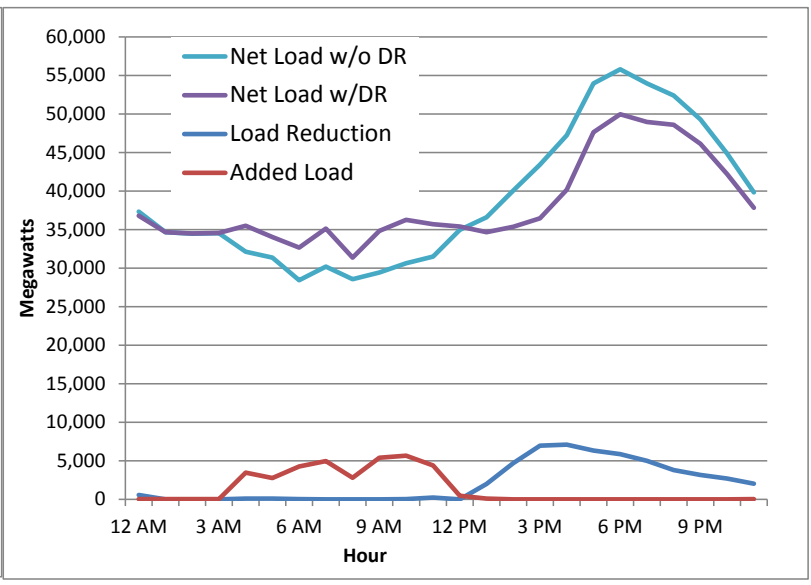

(b) July 27

Figure 25. Impact of additional demand response on system net load on March 29 and July 27

Further analysis is needed to estimate the actual potential for demand shifting and associated costs; however, there likely are additional opportunities for shiftable loads. As an example, the CAISO LTPP model includes about 1,200 MW of schedulable pumping loads. The pumping load profile in the LTPP model is pre-scheduled and generally corresponds to match historical (low-VG) demand profiles. The scheduled pumping load is highest during the traditional offpeak period in the early morning, and it drops by about $700 \mathrm{MW}$ in the late morning, exactly when the PV output increases and overgeneration may occur. Assuming there is flexibility when this pumping load can occur, re-scheduling this load could accommodate some additional PV.

Overall, based on the assumptions made in this simulation, the impact of load shifting and the increase in maximum penetration has modest impact on avoided curtailments. The impact of the added DR case on PV curtailment is illustrated in Figure 26. 


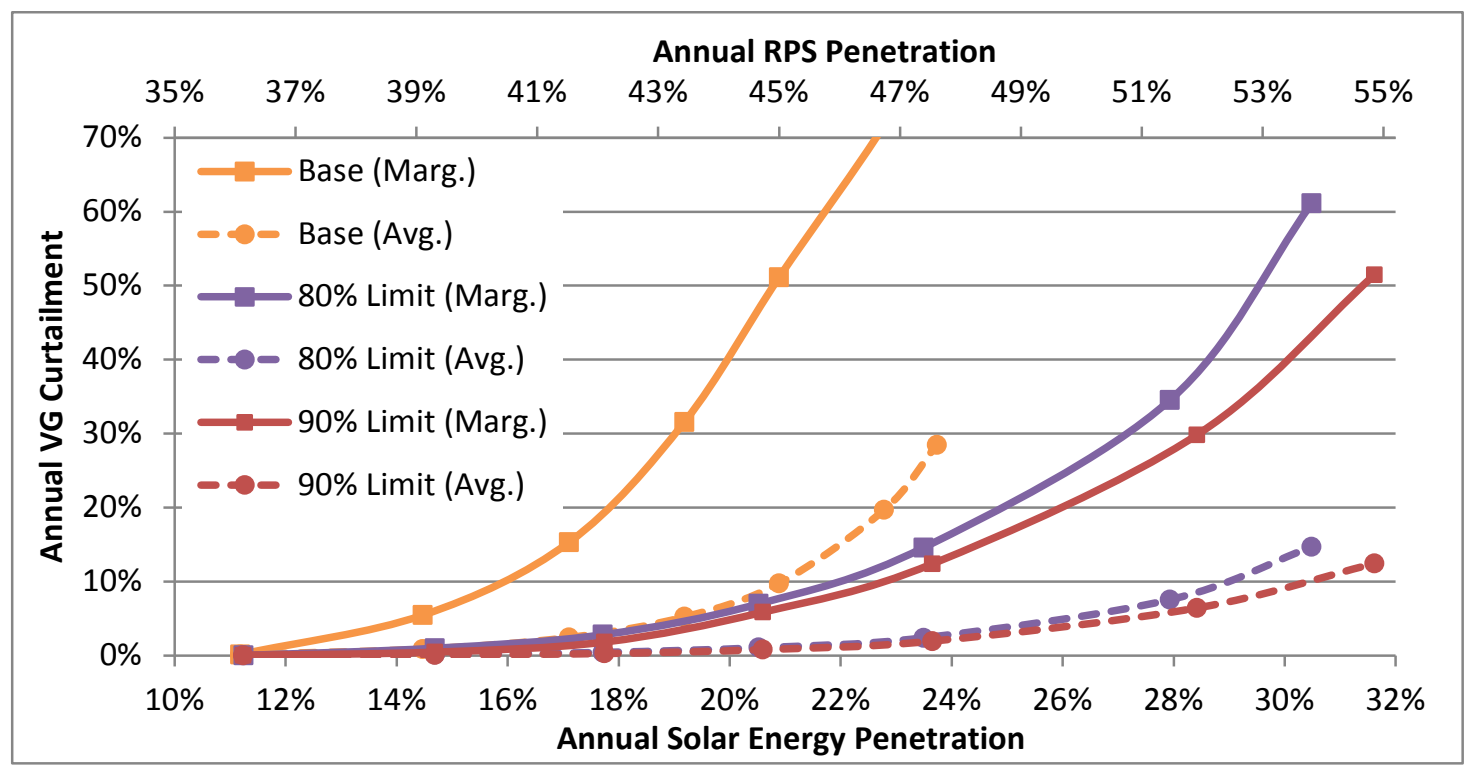

Figure 26. Marginal and average curtailment due to overgeneration under increasing penetration of PV in California after additional demand response and increasing maximum penetration to $90 \%$

The relatively modest reduction in PV curtailment observed moving to the $90 \%$ penetration limits is due to the constraints on thermal and hydro plant operations. The presence of baseload non-carbon resources in the system, including nuclear, geothermal, and hydro, in addition to must-run combined heat and power plants limits the maximum penetration of wind and solar to well under $90 \%$. During days with very high penetration of PV, nearly all the non-CHP fossilfueled thermal capacity in California is turned off for the 11 hours of solar production. However, the results in this section imply that deploying new communications and control technologies that allow distributed resources to participate in grid functions and could significantly increase PV potential. In these examples, total penetration of about $25 \%$ solar on an annual basis appears possible with about 5\% annual curtailment. 


\section{Additional Opportunities to Fatten and Flatten the Duck}

In the previous section, we indicate that near-term technology options are capable of helping mitigate challenges of the duck chart and increase solar penetration to as high as $25 \%$ with limited curtailment. Moving beyond this point with exclusively solar resources becomes increasingly challenging; however, several additional options can help fatten and flatten the duck. While we evaluated demand response in this work, further analysis of load shifting potential is needed, as we assume that during the hours of high VG output, less than $1.5 \%$ of total demand may be shifted over a period of hours or more.

Other options that have been suggested to address overgeneration include regional interchange, more flexible generation, and energy storage. While this analysis has significant interaction between California and neighboring states, additional interchange, including exports from California, could potentially further reduce curtailment (Nelson and Wisland 2015). This may require broader implementation of various market mechanisms that allow for exchanging energy across regions. ${ }^{30}$ A long-term challenge may occur when surrounding states also adopt increasing amounts of wind and PV, leading to regional surpluses of renewable energy during spring afternoons.

Finally, additional storage (beyond existing and mandated storage) could be used to shift load. In addition to electricity storage technologies such as batteries or pumped hydro, concentrating solar power using thermal energy storage can shift solar generation to periods of low PV output. Storage with high capacity value could enable further retirements of the thermal generation fleet that could reduce minimum generation constraints (Denholm and Mehos 2011). Finally, while this analysis focuses primarily on enabling high solar penetration, it should be noted that a more balanced portfolio could more generally reduce the challenges of integrating VG. When PV is at $25 \%$ penetration, additional wind (or non-VG renewables such as geothermal) has significantly lower levels of marginal curtailment than PV. This has been noted previously (E3 2014; Brinkman 2015), and it suggests the need for a more comprehensive analysis of different renewable portfolios to achieve the most cost effective mix of generation technologies.

\footnotetext{
${ }^{30}$ An example is the Western Energy Imbalance Market (https://www.caiso.com/informed/Pages/EIMOverview/Default.aspx).
} 


\section{Conclusions}

Accommodating increased levels of PV in California will require understanding and addressing changes in net load shape created by large power production over a relatively short period in the middle of the day. System planners and operators will need to consider changes to a system historically dominated by dispatchable thermal and hydro resources. In the near term, changes underway or proposed in California and elsewhere - such as shorter scheduling intervals, increased interaction across regions, and the creation of new market incentives for generator dispatch - will reduce the minimum generation challenge and enable greater utilization of VG. In the longer term, grid operators will need non-traditional resources to supply reserves and grid stability services. This shift in operating practices will in turn require system operators to have visibility and control of distributed PV, storage, and load, and it will likely require new market mechanisms to incentivize these resources to participate in providing grid services. Without utilizing PV or other distributed resources to provide grid services - which is technically feasible - excessive curtailment of PV could occur at penetrations well below $20 \%$ on an annual energy basis

Because of the limited coincidence of PV supply with demand, additional mechanisms will be needed to maximize load-shifting. Simple historical methods, such as time-of-use pricing with fixed price intervals will likely be insufficient to address the variability and uncertainty of the solar resource, which changes on a daily and hourly basis.

By using a combination of grid flexibility options, the duck shape of net load can be accommodated and shaped to allow annual PV penetrations that exceed $25 \%$, with limited curtailment, even without considering the impact of large-scale energy storage. Many of the needed grid flexibility options are already being deployed in various locations around the United States. Additional portfolio analysis can assist in designing a mix of VG resources and associated "enabling" technologies that could achieve very high penetration while maintaining grid reliability. 


\section{References}

Abrams, A., Fioravanti, R., Harrison, J., Katzenstein, W., Kleinberg, M., Lahiri, S., Vartanian, C. (DNV KEMA Energy \& Sustainability). 2013. Energy Storage Cost-effectiveness Methodology and Preliminary Results. California Energy Commission. Publication number: CEC-XXX-2010XXX.

Aho, J.; Buckspan, A.; Laks, J.; Fleming, P.; Yunho Jeong; Dunne, F.; Churchfield, M.; Pao, L.; Johnson, K., "A tutorial of wind turbine control for supporting grid frequency through active power control," American Control Conference (ACC), 2012 , vol., no., pp. 3120,3131, 27-29 June 2012. doi: 10.1109/ACC.2012.6315180

Bird, L.; J. Cochran; X. Wang (2014) Wind and Solar Energy Curtailment: Experience and Practices in the United States NREL/TP-6A20-60983

Bloom, A.; Townsend, A.; Palchak, D. (2015) Eastern Renewable Generation Integration Study: Flexibility and High Penetrations of Wind and Solar. NREL (National Renewable Energy Laboratory) NREL/PR-6A20-64795

Bouillon, B. (2014) Prepared Statement of Brad Bouillon on behalf of the California Independent System Operator Corporation UNITED STATES OF AMERICA BEFORE THE FEDERAL ENERGY REGULATORY COMMISSION Reliability Technical Conference Docket No. AD14-9-000. http://www.ferc.gov/CalendarFiles/20140610083142-Bouillon,\%20CAISO.pdf

Brinkman, G.; Jorgenson, J.; Ehlen, A.; Caldwell, J. (2015) “The California 2030 Low Carbon Grid Study,” TP- 6A20-64884

Brown, E.G, Jr. (2013). "Climate Change Scoping Plan: First Update-Discussion Draft for Public Review and Comment." Sacramento, CA: Prepared by the California Air Resources Board for the State of California. Accessed: January 24, 2014: http://www.arb.ca.gov/cc/scopingplan/2013 update/discussion_draft.pdf.

Brown, E.G., Jr. (2011). Letter prepared for the members of the California State Senate. SBX1 2 signing message. Sacramento, CA. Accessed: January 24, 2014: http://gov.ca.gov/docs/SBX1_0002_Signing_Message.pdf.

CAISO. (2010). Integration of Renewable Resources: Operational Requirements and Generation Fleet Capability at 20\% RPS. Folsom, CA. Accessed May 2, 2014: http://www.caiso.com/Documents/Integration-RenewableResourcesOperationalRequirementsandGenerationFleetCapabilityAt20PercRPS.pdf.

CAISO. (2011). Summary of Preliminary Results of 33\% Renewable Integration Study—2010 CPUC LTPP Docket No. R.10-05-006. Folsom, CA. Accessed May 2, 2014: http://www.cpuc.ca.gov/NR/rdonlyres/E2FBD08E-727B-4E84-BD987561A5D45743/0/LTPP_33pct_initial_results_042911_final.pdf.

CAISO. (2011a). "Track I Direct Testimony of Mark Rothleder on Behalf of the California Independent System Operator Corporation (Corrected)," Before the Public Utilities Commission 
of the State of California, Order Instituting Rulemaking to Integrate and Refine Procurement Policies and Consider Long-Term Procurement Plans, Rulemaking 10-05-006. Accessed March 27, 2013: http://www.caiso.com/Documents/2011-08-10_ErrataLTPPTestimony_R10-05006.pdf.

CAISO. (2012). 2011 Annual Report on Market Issues and Performance. Folsom, CA: https:/www.caiso.com/Documents/2011AnnualReport-MarketIssues-Performance.pdf.

CASIO (2013). What the Duck Curve Tells us about Managing a Green Grid. https://www.caiso.com/Documents/FlexibleResourcesHelpRenewables_FastFacts.pdf

California State Assembly Bill 2514, Energy Storage Systems, By Skinner, September 29, 2010, Section 9620, http://www.leginfo.ca.gov/pub/09-10/bill/asm/ab 25012550/ab_2514_bill_20100929_chaptered.pdf

California Public Utilities Commission Rulemaking 10-21-007, Order Instituting Rulemaking Pursuant to Assembly Bill 2514 to Consider the Adoption of Procurement Targets for Viable and Cost-Effective Energy Storage Systems., December 16, 2010, http://docs.cpuc.ca.gov/PUBLISHED/FINAL_DECISION/128658.htm

California Public Utilities Commission Decision 13-10-040, Decision adopting energy storage procurement framework and design program, October 17, 2013, http://docs.cpuc.ca.gov/PublishedDocs/Published/G000/M079/K533/79533378.PDF

California Energy Commission. (2011). Renewable Power in California: Status and Issues CEC150-2011-002-LCF-REV1. Sacramento, CA. Accessed May 2, 2014: http://www.energy.ca.gov/2011publications/CEC-150-2011-002/CEC-150-2011-002LCF-REV1.pdf.

California Energy Commission. (2014). California Electricity Statistics and Data. Sacramento, CA. Accessed: January 30, 2014: http://energyalmanac.ca.gov/electricity/electricity generation.html.

Cochran, J.; P. Denholm, B. Speer, and M. Miller (2015) Grid Integration and the Carrying Capacity of the U.S. Grid to Incorporate Variable Renewable Energy. NREL Report No. NREL/TP-6A20-62607

CPUC. (2013). Order Instituting Rulemaking Pursuant to Assembly Bill 2514 to Consider the Adoption of Procurement Targets for Viable and Cost-Effective Energy Storage Systems. Decision 13-10-040 (October 17). Accessed May 2, 2014: http://docs.cpuc.ca.gov/PublishedDocs/Published/G000/M079/K533/79533378.PDF.

Denholm, P.; Margolis, R.; Palmintier, B.; Barrows, C.; Ibanez, E.; Bird, L. (2014). Methods for Analyzing the Benefits and Costs of Distributed Photovoltaic Generation to the U.S. Electric Utility System. NREL Report No. TP-6A20-62447.

Denholm, P.; Wan, Y-H.; Hummon, M.; Mehos, M. (2013). An Analysis of Concentrating Solar Power with Thermal Energy Storage in a California 33\% Renewable Scenario. NREL/TP-6A20- 
58186. Golden, CO: National Renewable Energy Laboratory. Access May 2, 2014: http://www.nrel.gov/docs/fy13osti/58186.pdf.

Denholm, P.; Mehos, M. (2011). Enabling Greater Penetration of Solar Power via the Use of Thermal Energy Storage. NREL/TP-6A20-52978. Golden, CO: National Renewable Energy Laboratory. Accessed May 2, 2014: http://www.nrel.gov/csp/pdfs/52978.pdf.

Edmunds, T., A. Lamont, V. Bulaevskaya, C. Meyers, J. Mirocha, A. Schmidt, M. Simpson, S. Smith, P. Sotorrio, P. Top and Y. Yao (2013). The Value of Energy Storage and Demand Response for Renewable Integration in California, California Energy Commission, CEC-500-10051.

Energy and Environmental Economics, Inc. (2014). Investigating a Higher Renewables Portfolio Standard in California. San Francisco, CA: January. Accessed May 2, 2014: https://ethree.com/documents/E3 Final_RPS_Report 20140106 with appendices.pdf.

ERCOT 2014. Demand Response in ERCOT. 2014 Operators Training Seminar. http://www.ercot.com/services/training/archives.

GE Energy (2010). Western Wind and Solar Integration Study. NREL/SR-550-47434. Golden, CO: NREL. Accessed January 2013: http://www.nrel.gov/docs/fy10osti/47434.pdf.

Gevorgian, V.; Zhang, Y.; Ela, E. (2015). Investigating the Impacts of Wind Generation Participation in Interconnection Frequency Response IEEE Transactions on Sustainable Energy Vol. 6 (3) July 2015 pp. 1004-1012.

Jorgenson, J., P. Denholm, and M. Mehos. (2014). Estimating the Value of Utility-Scale Solar Technologies in California under a 40\% Renewable Portfolio Standard. NREL Report No. TP6A20-61685.

Lazar, J. (2014). Teaching the Duck to Fly. Regulatory Assistance Project.

Lew, D., M. Schroder, N. Miller, and M. Lecar. 2015. Integrating higher levels of variable energy resources in California. Schenectady, NY: GE Energy Consulting. Online at http://www.largescalesolar.org/files/Final-CA-VER-Integration-6-15-15.pdf.

Lew, D.; Brinkman, G.; Ibanez, E.; Florita, A.; Heaney, M.; Hodge, B.-M.; Hummon, M.; Stark, G.; King, J.; Lefton, S.A.; Kumar, N.; Agan, D.; Jordan, G.; Venkataraman, S. (2013). The Western Wind and Solar Integration Study: Phase 2. NREL/TP-5500-55588. Golden, CO: National Renewable Energy Laboratory. Accessed May 2, 2014: http://www.nrel.gov/docs/fy13osti/55588.pdf.

Liu, S. 2014a. Phase 1.A. Direct testimony of Dr. Shucheng Liu on behalf of the California Independent System Operator Corporation. Proceeding R.13-12-010, August 13. San Francisco, CA: California Public Utilities Commission. Online at http://www.caiso.com/Documents/Aug13 2014 InitialTestimony_ShuchengLiu Phase1A_LT PP R13-12-010.pdf. 
Liu, S. 2014b. Phase 1.A. reply testimony of Dr. Shucheng Liu on behalf of the California Independent System Operator Corporation. Proceeding R.13-12-010, October 22. San Francisco, CA: California Public Utilities Commission. Online at http://www.caiso.com/Documents/Oct22_2014_ReplyTestimony_ShuchengLiu_Phase1ALon g-TermProcurementPlans_R13-12-010.pdf.

Liu, S. 2014c. Review of the ISO 2014 LTPP System Flexibility Study. Online at https://www.caiso.com/Documents/Presentation_2014LTPPSystemFlexibilityStudy_SHcall.pd $\underline{\mathrm{f}}$

Mao, M., and Galjanic, T. 2014. Revised Phase 1A testimony of Southern California Edison Company on resource need. Proceeding R.13-12-010, September 12. San Francisco, CA: California Public Utilities Commission.

N. W Miller; M Shao; S Pajic; R D'Aquila; Western Wind and Solar Integration Study Phase 3 -Frequency Response and Transient Stability. NREL/SR-5D00-62906 External Note: Work performed by GE Energy Management, Schenectady, New York

Mills, A.; Wiser, R. (June 2012a). Changes in the Economic Value of Variable Generation at High Penetration Levels: A Pilot Case Study of California. LBNL-5445E. Berkeley, CA: Ernest Orlando Lawrence Berkeley National Laboratory. Accessed May 2, 2014: http://emp.lbl.gov/sites/all/files/lbnl-5445e.pdf.

Mills, A.; Wiser, R. (2012a). An Evaluation of Solar Valuation Methods Used in Utility Planning and Procurement Processes. LBNL-5933E. Berkeley, CA: Ernest Orlando Lawrence Berkeley National Laboratory. Accessed May 2, 2014: http://emp.lbl.gov/sites/all/files/lbnl-5933e 0.pdf.

Mills, Andrew D., and Ryan H. Wiser. "Strategies to mitigate declines in the economic value of wind and solar at high penetration in California." Applied Energy 147 (2015): 269-278.

Nelson, J. 2014. Prepared opening testimony of Dr. Jimmy Nelson on behalf of the Union of Concerned Scientists and Sierra Club, including Errata. Proceeding R.13-12-010, September 24. San Francisco, CA: California Public Utilities Commission. Online at https://content.sierraclub.org/coal/sites/content.sierraclub.org.coal/files/docs/2014-0930\%20Testimony $\% 20$ Dr. $\% 20$ Jimmy $\% 20$ Nelson $\% 20$ on $\% 20$ behalf $\% 20$ of $\% 20$ the $\% 20$ UCS $\% 20$ an d\%20SC.pdf.

Nelson, J. and L. Wisland. (2015) Achieving 50 Percent Renewable Electricity in California. Union of Concerned Scientists. Online at www.ucsusa.org/California50RPSanalysis.

Sterling, J.; McLaren, J.; Taylor, M.; Cory, K. (2013). Treatment of Solar Generation in Electric Utility Resource Planning. NREL Report No. TP-6A20-60047. Golden, CO: National Renewable Energy Laboratory. 